\title{
Selective synaptic connections in the retinal pathway for night vision
}

\section{Deborah L. Beaudoin $^{1}$ ｜ Mania Kupershtok ${ }^{1}$ | Jonathan B. Demb1,2,3,4}

${ }^{1}$ Department of Ophthalmology \& Visual Sciences, University of Michigan, Ann Arbor, Michigan

${ }^{2}$ Department of Molecular, Cellular \& Developmental Biology, University of Michigan, Ann Arbor, Michigan

${ }^{3}$ Department of Ophthalmology \& Visual Science, Yale University, New Haven, Connecticut

${ }^{4}$ Department of Cellular \& Molecular Physiology, Yale University, New Haven, Connecticut

\section{Correspondence}

Jonathan B. Demb, Department of Ophthalmology \& Visual Science, Yale University, New Haven, CT 06511.

Email: jonathan.demb@yale.edu

Funding information $\mathrm{NIH}$, Grant Number: EY014454, EY07003, EY026878; Research to Prevent Blindness, unrestricted awards to University of Michigan and Yale University.

\begin{abstract}
The mammalian retina encodes visual information in dim light using rod photoreceptors and a specialized circuit: rods $\rightarrow$ rod bipolar cells $\rightarrow$ All amacrine cell. The All amacrine cell uses signconserving electrical synapses to modulate ON cone bipolar cell terminals and sign-inverting chemical (glycinergic) synapses to modulate OFF cone cell bipolar terminals; these ON and OFF cone bipolar terminals then drive the output neurons, retinal ganglion cells (RGCs), following light increments and decrements, respectively. The All amacrine cell also makes direct glycinergic synapses with certain RGCs, but it is not well established how many types receive this direct All input. Here, we investigated functional All amacrine $\rightarrow$ RGC synaptic connections in the retina of the guinea pig (Cavia porcellus) by recording inhibitory currents from RGCs in the presence of ionotropic glutamate receptor (iGluR) antagonists. This condition isolates a specific pathway through the All amacrine cell that does not require iGluRs: cone $\rightarrow$ ON cone bipolar cell $\rightarrow$ All amacrine cell $\rightarrow$ RGC. These recordings show that All amacrine cells make direct synapses with OFF Alpha, OFF Delta and a smaller OFF transient RGC type that co-stratifies with OFF Alpha cells. However, All amacrine cells avoid making synapses with numerous RGC types that co-stratify with the connected RGCs. Selective All connections ensure that a privileged minority of RGC types receives direct input from the night-vision pathway, independent from OFF bipolar cell activity. Furthermore, these results illustrate the specificity of retinal connections, which cannot be predicted solely by co-stratification of dendrites and axons within the inner plexiform layer.
\end{abstract}

\section{KEYWORDS}

All amacrine cell, retina, retinal ganglion cells, rod bipolar cell, scotopic vision, synapse, RRID: AB_2079751, RRID: AB_2536190, RRID: AB_2307351, RRID: AB_2315776

\section{1 | INTRODUCTION}

Mammalian retinal circuitry comprises parallel pathways for visual processing (Demb \& Singer, 2015; Euler, Haverkamp, Schubert, \& Baden, 2014). At the first stage, the photoreceptor array includes rods and cones, which are specialized for encoding either dim or bright light, respectively. Rods and cones make selective synaptic connections with dedicated glutamatergic interneurons, the bipolar cells (Euler et al., 2014). Rod bipolar cells receive inputs exclusively from rods and are ON-type cells, that is, they depolarize to light increments. Cone bipolar cells receive inputs primarily or exclusively from cones and they are either ON- or OFF-type cells, that is, they depolarize to either light increments or decrements. The ON or OFF response depends on the bipolar cell's glutamate receptors: metabotropic type 6 (mGluR6) for
ON bipolar cells and ionotropic (iGluR) for OFF bipolar cells (Euler et al., 2014). Cone bipolar cells further divide into over a dozen types with unique patterns of morphology, protein expression, and light response (Borghuis, Marvin, Looger, \& Demb, 2013; Euler et al., 2014; Franke et al., 2017; Ichinose \& Hellmer, 2016; Lindstrom, Ryan, Shi, \& DeVries, 2014; Shekhar et al., 2016; Wässle, Puller, Müller, \& Haverkamp, 2009). Furthermore, some OFF cone bipolar cell types receive a portion of their synapses directly from rods (Behrens, Schubert, Haverkamp, Euler, \& Berens, 2016; Euler et al., 2014; Hack, Peich, \& Brandstätter, 1999; Li, Keung, \& Massey, 2004; Pang, Gao, Paul, \& Wu, 2012; Protti, Flores-Herr, Li, Massey, \& Wässle, 2005; Soucy, Wang, Nirenberg, Nathans, \& Meister, 1998).

Rod and cone bipolar cells differ markedly in their postsynaptic partners. Cone bipolar cells make synapses with retinal ganglion cells 

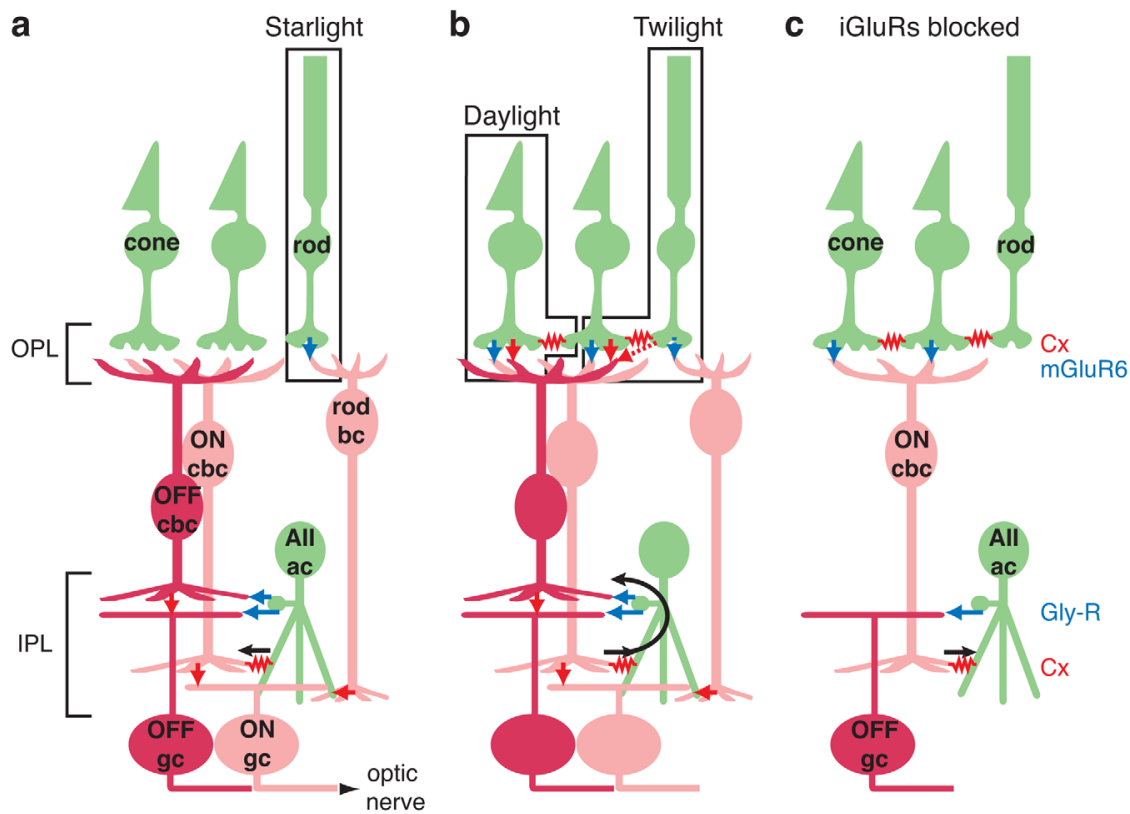

FIGURE 1 Night vision circuit in mammalian retina. (a) In starlight, rods signal to the rod bipolar cell (bc) via glutamate release onto mGluR6 receptors (blue arrow). The rod bc releases glutamate onto iGluRs on the All amacrine cell (All ac; red arrow). The All ac forms two types of output synapse: an electrical gap junction, formed by connexins (Cx), with ON cone bipolar cell (cbc) terminals (red resistor symbol) and glycine release onto OFF cbc and OFF ganglion cell (gc) dendrites (blue arrows). ON and OFF cbc's release glutamate onto iGluRs of the corresponding gc type (red arrows). Abbreviations: $\mathrm{OPL}=$ outer plexiform layer; IPL = inner plexiform layer. (b) In twilight, rods signal cones through gap junctions. Under these conditions and in daylight, when cones are stimulated directly, cones signal through glutamate release onto iGluRs and mGluRs at OFF and ON cbc synapses, respectively. In the IPL, ON cbc's excite the All ac and cause glycine release onto OFF cbc terminals and OFF gc dendrites. (c) In the presence of iGluR blockers, the ability to drive light-evoked gc responses is limited to a circuit where cones stimulate the ON cbc (via mGluR6 receptors), which drives the All (via a gap junction) to release glycine onto OFF-layer gc dendrites. Rods can also drive this circuit through their gap junctions with cones

(RGCs), the output neurons of the retina, whereas rod bipolar cells instead make synapses with a specialized interneuron, the All amacrine cell (Bloomfield \& Dacheux, 2001; Demb \& Singer, 2012). The rod bipolar cell is an ON-type cell and depolarizes the All at light onset (Ke et al., 2014; Nelson, 1982; Singer \& Diamond, 2003). The All cell enables communication between the rod system and both ON and OFF pathways of the cone system using two categories of output synapse (Figure 1a). The All arboreal dendrites electrically couple to the ON cone bipolar terminals in the inner half of in the inner plexiform layer (IPL), thereby mediating glutamate release at light onset. Additionally, depolarization at light onset causes $\mathrm{Ca}$ influx through voltage-gated Ltype channels into All lobular appendages (Balakrishnan, Puthussery, Kim, Taylor, \& von Gersdorff, 2015; Habermann, O'Brien, Wässle, \& Protti, 2003); these lobules in turn release glycine onto OFF cone bipolar terminals in the outer half of the IPL, thereby inhibiting the OFF system at light onset (Mazade \& Eggers, 2013). The relief of this inhibition from OFF cone bipolar terminals mediates glutamate release at light offset (Borghuis, Looger, Tomita, \& Demb, 2014; Demb \& Singer, 2012; Müller, Wässle, \& Voigt, 1988).

In addition to their numerous synapses with cone bipolar terminals, All amacrine cells make a smaller number of glycinergic synapses with RGC dendrites (Anderson et al., 2011; Demb \& Singer, 2012; Kolb \& Nelson, 1993; Marc, Anderson, Jones, Sigulinsky, \& Lauritzen, 2014; Strettoi, Raviola, \& Dacheux, 1992). These All $\rightarrow$ RGC synapses can be studied using patch clamp recording in bright light, because the cone bipolar system co-opts the All circuit for a separate purpose in daylight vision. In bright light, cones drive ON cone bipolar cells to stimulate All amacrine cells through the electrical synapse in a direction opposite to that in the night vision circuit (Figure 1b). Notably, the cone $\rightarrow \mathrm{ON}$ cone bipolar $\rightarrow$ All $\rightarrow$ OFF RGC circuit uses mGluRs, electrical synapses and glycinergic synapses, respectively, and does not require an iGluR (Beaudoin, Manookin, \& Demb, 2008; Cohen, 1998; Ke et al., 2014; Manookin, Beaudoin, Ernst, Flagel, \& Demb, 2008; Münch et al., 2009; Murphy \& Rieke, 2008; Pang et al., 2007; Trexler, Li, \& Massey, 2005; Xin \& Bloomfield, 1999) (Figure 1c). This differs from virtually every other circuit in the retina between photoreceptors and RGCs, which require at least one iGluR, that is, at photoreceptor $\rightarrow$ OFF bipolar cell, bipolar cell $\rightarrow$ (non-All) amacrine cell, and bipolar $\rightarrow$ RGC synapses (Chen \& Diamond, 2002; DeVries, 2000; Manookin, Weick, Stafford, \& Demb, 2010; Miller, 2008). Among amacrine cells, the All has a unique mechanism for light-mediated responses, independent from iGluRs, because of its strong electrical coupling with $\mathrm{ON}$ cone bipolar terminals (Cohen \& Sterling, 1990; Deans, Volgyi, Goodenough, Bloomfield, \& Paul, 2002; Lin, Jakobs, \& Masland, 2005; Maxeiner et al., 2005; Mills \& Massey, 1995; Mills et al., 2001; Veruki \& Hartveit, 2002).

By recording light-evoked inhibition in the presence of iGluR antagonists, it has been shown that All cells release onto specific RGC types. In the mouse, this includes monostratified OFF Alpha (OFF-T) 
and OFF Delta (OFF-S) RGCs that could be readily targeted based on their large soma size (Ke et al., 2014; Münch et al., 2009; Murphy \& Rieke, 2008; van Wyk, Wässle, \& Taylor, 2009). Furthermore, a bistratified RGC type, the suppressed-by-contrast $(\mathrm{SbC})$ cell also apparently receives a direct input (Jacoby, Zhu, DeVries, \& Schwartz, 2015). In the guinea pig, the OFF Alpha cell receives a direct input from the All amacrine cell (Beaudoin et al., 2008; Manookin et al., 2008), and it was proposed that a second type, the G5 RGC, does as well based on the sensitivity of its inhibition to a gap junction blocker (Liang \& Freed, 2010). However, it is not well understood how commonly RGC types receive direct All synapses, because most studies have focused on a small number of types. EM studies suggest that the All lobules frequently make physical contact with RGC dendrites but lack synaptic specializations, suggesting that the All may form synapses with only a few privileged RGC types (Marc et al., 2014).

Here, we targeted small cell bodies in the guinea pig retina to sample an array of RGC types beyond the most commonly studied types with large cell bodies. We identified All synaptic connections based on persistent inhibitory synaptic input in the presence of iGluR antagonists. Our results suggest that a small fraction of RGC types receive direct input from the All amacrine cell, enabling a direct connection for night vision independent of OFF bipolar terminals (Figure 1a); this direct All connection would also mediate inhibition at light onset for twilight and daylight vision (Figure 1b). More generally, our results show that co-stratification of RGC dendrites is insufficient to predict connectivity with Alls, ruling out a simple principle whereby proximity predicts connectivity in the retina's IPL (Peters \& Feldman, 1976; Stepanyants \& Chklovskii, 2005).

\section{MATERIALS AND METHODS}

\subsection{Tissue preparation and electrophysiology}

The experimental protocol was the same as that described in detail previously (Beaudoin, Borghuis, \& Demb, 2007; Beaudoin et al. 2008; Manookin et al., 2008). Briefly, a Hartley guinea pig, housed in a $12 / 12$ $\mathrm{hr}$ light/dark cycle, was anesthetized with ketamine $(100 \mathrm{mg} / \mathrm{kg})$ and xylazine $(10 \mathrm{mg} / \mathrm{kg})$ in dim red light. The animal was then decapitated, the eyes were removed, and the retinas were hemisected in dim white light using a dissection microscope. All procedures conformed to the National Institutes of Health and University of Michigan guidelines for use and care of animals in research. Each retina was prepared as an eyecup, with the retinal pigment epithelium and sclera attached and was typically cut in half along the vertical midline. For each piece of retina, a single cell was studied on the dorsal side, and drugs were applied only once. The retina was mounted on filter paper, with holes punched to allow through transmitted light. The piece of retina was stored in carbogenated $\left(95 \% \mathrm{O}_{2}, 5 \% \mathrm{CO}_{2}\right)$ Ames medium (Sigma) in a dark container until the time of recording, at which point it was maintained in a chamber on a microscope stage and superfused $(6 \mathrm{ml} / \mathrm{min})$ with Ames medium heated to $33-35^{\circ} \mathrm{C}$.

The retina and patch electrode were visualized using a CCD camera, as described previously, mounted on an Olympus BX51WI microscope. Most cells were targeted based on small soma size $(<20$ $\mu \mathrm{m}$ diameter) to complement previous recordings of cells with larger soma size; however, some cells with large somas were also recorded for comparison. The patch electrode (tip resistance, 3-6 $\mathrm{M} \Omega$ ) was filled either with Ames medium, for loose patch recording of spikes, or an intracellular recording solution, for whole-cell voltage-clamp measurements. The intracellular solution contained (in mM): 120 cesiummethanesulfonate, 5 tetraethylammonium (TEA)-Cl, 10 HEPES, $3 \mathrm{NaCl}$, 10 BAPTA, 2 QX314-Cl, 2 ATP-Mg ${ }^{2+}, 0.3 \mathrm{GTP} \mathrm{Na}^{+}$and 0.1\% Lucifer Yellow, titrated to $\mathrm{pH}$ 7.3. Chemicals were purchased from either Sigma or Invitrogen. The iGluR antagonists CNQX (200 $\mu \mathrm{M})$ or DNQX $(100 \mu \mathrm{M})$ and D-AP5 $(100 \mu \mathrm{M})$, purchased from Tocris Biosciences, were added to the Ames medium to isolate a presumed contribution from the All amacrine cell circuit (Manookin et al., 2008).

Membrane current was recorded at $10 \mathrm{kHz}$ using a MultiClamp 700A amplifier, Digidata 1322A analog-to-digital board and pClamp 9 software (Molecular Devices). Junction potential $(-9 \mathrm{mV}$ ) was corrected, as was an error in the holding potential introduced by series resistance, as described previously (Manookin et al., 2008, 2010). Recordings were typically made at five or more holding potentials. Excitatory currents were recorded at or near the presumed reversal of inhibitory $\mathrm{Cl}$ channels $\left(E_{\mathrm{inh}}=-67 \mathrm{mV}\right)$, and inhibitory currents were recorded at or near the presumed reversal of excitatory cation channels $\left(E_{\text {exc }}=0 \mathrm{mV}\right)$. In many cases, recordings were made at holding potentials within $15 \mathrm{mV}$ on either side of the exact reversal potential, and the final measurement represents a weighted average relative to the difference of each holding potential from the reversal potential. For example, the average inhibitory current would weight recording at -5 $\mathrm{mV}$ and $+10 \mathrm{mV}$ in a 2:1 ratio. Synaptic current measurements were converted to synaptic conductance after dividing the current by the driving force: $-67 \mathrm{mV}$ for excitatory current and $+67 \mathrm{mV}$ for inhibitory current.

\section{2 | Visual stimulus and analysis}

A visual stimulus was displayed on a miniature monochrome monitor $(640 \times 480$ pixels, $60 \mathrm{~Hz}$ vertical refresh; Lucivid MR1-103; Microbrightfield) projected through the $4 \times$ objective lens and focused on the photoreceptors, as described previously (Manookin et al., 2008). The output was linearized using a gamma correction and the stimulus was generated using MATLAB (Mathworks) and the psychophysics toolbox (Brainard, 1997). Based on prior calculations, we estimate that the mean luminance generates $\sim 10^{4}$ photoisomerizations $\left(P^{*}\right)$ per rod and $\sim 5 \times 10^{3} \mathrm{P}^{*}$ per $\mathrm{M}$-cone, which dominate the superior retina (Yin et al., 2006). Thus, the stimuli generate a mix of rod and cone responses with a strong stimulation of cone bipolar cell circuitry (Beaudoin et al., 2008; Manookin et al., 2008).

After locating a soma, a loose-patch spike recording was made of contrast-reversing spots of different diameters (200,400,600, and $800 \mu \mathrm{m})$ and contrast-reversing square-wave gratings $(400,800,1,200$, and 1,600 $\mu \mathrm{m}$ diameter grating patch, spatial frequency $5.3 \mathrm{cycles} / \mathrm{mm}$ ) presented for $3 \mathrm{~s}$ each. Stimuli were $100 \%$ contrast with a $1-\mathrm{Hz}$ reversal frequency. Direction-selective (DS) cells were identified using 
TABLE 1 Primary antibodies

\begin{tabular}{lllll} 
Antibody & Host & Antigen/species & Source & Catalog no. \\
ChAT & Goat & $\begin{array}{c}\text { Human placenta purified choline } \\
\text { acetyltransferase }\end{array}$ & Millipore & $\begin{array}{c}\text { AB144P } \\
\text { RRID: AB_2079751 }\end{array}$ \\
Lucifer Yellow & Rabbit & Lucifer Yellow & ThermoFisher Scientific & A-5750 \\
& & & & RRID: AB_2536190 \\
\hline
\end{tabular}

stimuli that moved in eight or twelve equally spaced directions. One stimulus was a moving light bar $(100 \times 200 \mu \mathrm{m})$ that moved along their long edge at $0.5 \mathrm{~mm} \mathrm{~s}^{-1}$. A second stimulus was a drifting squarewave grating $\left(1.6 \times 1.6 \mathrm{~mm}\right.$ patch; spatial frequency 5.3 cycles $\mathrm{mm}^{-1}$; $1-\mathrm{Hz}$ temporal frequency). Stimuli were $100 \%$ Weber contrast (bar stimulus) or Michelson contrast (grating stimulus).

Cells were classified as ON, OFF or ON-OFF based on spike responses to the contrast-reversing spots. The DS cells corresponded to the ON-OFF and ON types identified previously in guinea pig and other species (Koch et al., 2006; Vaney, Sivyer \& Taylor, 2012). Some cells also showed apparent orientation selectivity, as described in Results.

Following spike recordings, the cell was recorded with a second electrode in whole-cell voltage-clamp mode. Responses were measured to a contrast-reversing spot (100\% Michelson contrast, $1-\mathrm{Hz}, 200-\mu \mathrm{m}$ diameter) presented for $4 \mathrm{~s}$ at each of several holding potentials. The response to the spot was the average of the last three cycles of the 4-s stimulus and is plotted relative to the holding current measured before stimulus onset. This experiment was repeated after blocking iGluRs.

\section{3 | Confocal imaging}

The morphology of recorded cells was studied using methods described in detail previously (Manookin et al., 2008). Following a voltage-clamp recording, the piece of retina was fixed in $4 \%$ paraformaldehyde in $0.1 \mathrm{M} \mathrm{PBS}$ at room temperature. The tissue was subsequently incubated in $6 \%$ normal donkey serum (NDS; $1 \mathrm{hr}$ ) and $1 \%$ Trixon X-100; rinsed and incubated overnight at $4^{\circ} \mathrm{C}$ in blocking buffer (2\% NDS; $0.2 \%$ Triton X-100 in 0.05 M TBS), goat anti-ChAT polyclonal antibody (1:200 dilution; Millipore; RRID: AB_2079751) and rabbit anti-Lucifer Yellow polyclonal antibody (1:2,000 dilution; ThermoFisher Scientific; RRID: AB_2536190) (Table 1). These primary antibodies were used to label the ChAT bands and the filled RGC, respectively; both have been used in numerous previous studies for this purpose (Manookin et al., 2008; Park et al., 2015). The tissue was subsequently rinsed and incubated in secondary antibodies: donkey anti-goat-Cy3 (1:200 dilution; Jackson ImmunoResearch; RRID: AB_2307351) and donkey anti-rabbit-FITC (1:400 dilution; Jackson ImmunoResearch; RRID: AB_2315776) (Table 2) in blocking buffer. The tissue was rinsed and incubated in $0.2 \%$ ToPro-3 iodide (Invitrogen) in 0.1 M PBS, rinsed and then mounted with Vectashield (Vector Laboratories) and coverslipped. Glass spacers were inserted on either side of the tissue to prevent compression (Manookin et al., 2008).

A filled cell was imaged with an Olympus FluoView 300 confocal microscope, as described previously (Manookin et al., 2008). The dendritic field of the cell was captured with a $40 \times$ oil objective (NA, 1.3). The z-stack ( $2-\mu \mathrm{m}$ interval) was projected, and, when necessary, multiple images were assembled in Adobe Photoshop. The dendritic field area was estimated by drawing a polygonal boundary around the tips of the peripheral dendrites. We report the diameter of a circle with the same area as the measured polygon.

To measure dendritic tree stratification, one or two z-stacks were taken at higher resolution (60× oil objective, NA 1.4) at $0.5-\mu \mathrm{m}$ intervals. Within these stacks, we measured the fluorescence profiles as a function of slice number for between three and nine $46 \times 46 \mu \mathrm{m}$ regions of interest. These were positioned within peripheral dendrites, away from the primary dendrites rising from the soma. Peak fluorescence was determined using methods described previously for the filled cell and for two bands defined by cholinergic acetyltransferase (ChAT) immunofluorescence, which we refer to as the ChAT bands (Figure 2a,b) (Manookin et al., 2008; Park et al., 2015). We measured the position of a filled cell's dendrites relative to the ChAT bands, where 0 is the position of the inner ChAT band, representing the dendrites of ON-type starburst amacrine cells; and 1 is the position of the outer ChAT band, representing the dendrites of OFF-type starburst amacrine cells (Manookin et al., 2008). We analyzed cell morphology by plotting dendritic field diameter versus the normalized stratification of the dendrites relative to the ChAT bands (Figure 2c).

\section{3 | RESULTS}

A major objective of this study was to sample a range of RGC types that could be identified based on a combination of structural and functional criteria and then assayed for a direct All amacrine cell connection. To this end, we report on recordings from 108 RGCs in the guinea pig retina. This included 28 RGCs with large cell bodies ( $>20 \mu \mathrm{m}$ diameter),

TABLE 2 Secondary antibodies

\begin{tabular}{|c|c|c|c|c|}
\hline Antibody & Source & Catalog no. & Species & Dilution \\
\hline Cy3-conjugated donkey IgG & Jackson ImmunoResearch & $\begin{array}{l}705-165-147 \\
\text { RRID: AB_2307351 }\end{array}$ & Goat & $1: 200$ \\
\hline FITC-conjugated donkey IgG & Jackson ImmunoResearch & $\begin{array}{l}\text { 711-095-152 } \\
\text { RRID: AB_2315776 }\end{array}$ & Rabbit & $1: 400$ \\
\hline
\end{tabular}





FIGURE 2 Dendritic tree size and stratification distinguish RGC types. (a) Side-projection of a region of interest (46 $\times 46 \mu \mathrm{m})$ from the confocal z-stack of a monostratified RGC (OFF T2-L7 cell; boxed area in Figure 4f). Image at left shows the fluorescent intensity of the filled dendrite; the profile of fluorescence is shown in green, in normalized units. The fluorescence peak was fitted with a polynomial function (black line); the peak of the polynomial indicates the stratification level (black arrow, circle). Image at right shows the fluorescent intensity of the ChAT staining from the same section. The two peaks indicate the inner and outer ChAT bands, as labeled, and the dashed lines indicate the peaks of the fitted polynomial functions (black lines). (b) Same format as (a) for an example bistratified RGC (ON-OFF LB1L3.5/L8 cell; boxed area in Figure 5d). (c) Each data point represents a single cell and shows its dendritic tree diameter plotted against peak stratification of dendrites relative to the ChAT bands (straight dashed lines). Symbols indicate the presumed RGC type based on a combination of the parameters measured here and the measurements of excitatory conductance in response to a contrast-reversing spot, the input resistance, and the tuning to motion direction measured in subsequent figures. In addition to cells recorded in this study, cells from a previous study were included for four of the cell types (filled symbols; ON Alpha-L3, ON DS-L4, OFF Alpha-L7, OFF Delta-L9; Manookin et al., 2008). Ovals drawn with dashed lines show groups that became apparent based on the morphology measurements alone. In some cases, these groups included more than one cell type (e.g., OFF T1-L7 and OFF T2-L7) that became distinguishable after analyzing physiological responses. Layers of the retina are indicated by the scale in green (L1 - 10); the ChAT bands were aligned with L4 and L7.5, based on previous measurements (Manookin et al., 2008; see "Results" section). For bistratified cells, measurements of inner and outer dendrites are connected by a line

which comprised OFF Alpha ( $n=10)$, OFF Delta $(n=9)$, and ON Alpha cells $(n=9)$. These RGC types have been described in detail previously (Demb, Zaghloul, Haarsma, \& Sterling, 2001; Homann \& Freed, 2017; Manookin et al., 2008, 2010). In addition, we targeted smaller cell bodies ( $n=80$ cells). For most cells with small somas, and a subset with large somas, we obtained confocal images and characterized two parameters of the dendritic field, the diameter and the level of stratification $(n=86$ cells). Example measurements of dendrite stratification are shown in a side projection of a region of interest $(46 \times 46 \mu \mathrm{m}$; see "Materials and
Methods" section) within the confocal z-stack of a monostratified RGC (Figure 2a) and a bistratified RGC (Figure 2b). Dendrite stratification was normalized to the position of the inner and outer ChAT bands, which mark the ON and OFF starburst amacrine cell dendrites, respectively, and roughly divide the IPL into thirds (Manookin et al., 2008; Figure 2c).

We refer to stratification below by layers, where Layer 1 (L1) indicates the boundary between the IPL and the ganglion cell layer (GCL) and Layer 10 (L10) indicates the boundary between the IPL and the inner nuclear layer (INL). In this context, the ChAT bands were 
a

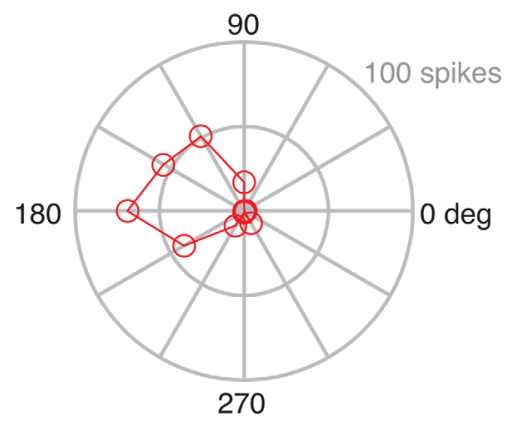

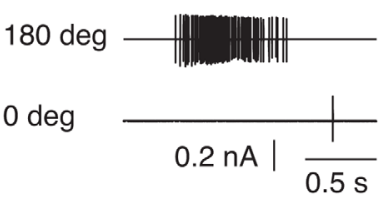

C

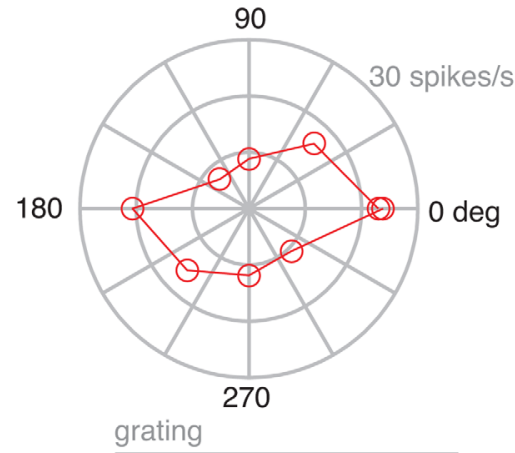

0 deg
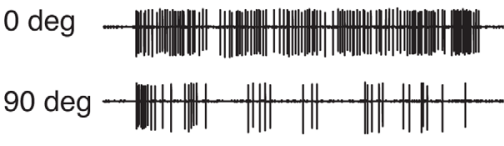

b

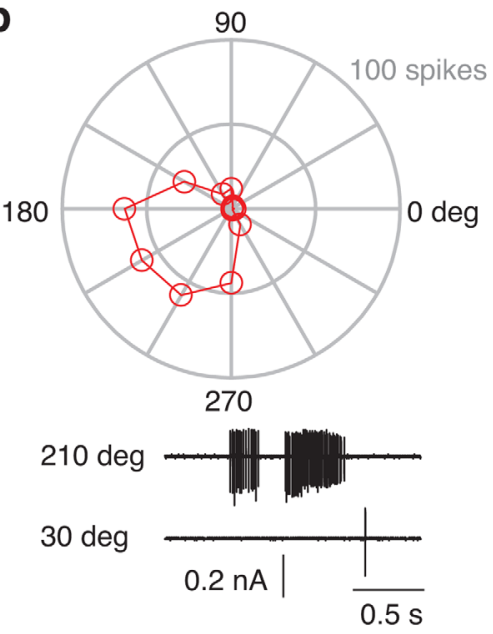

d
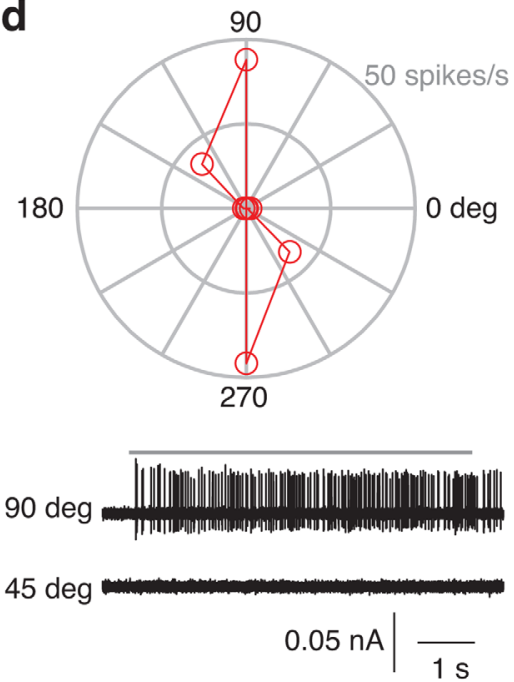

FIGURE 3 Direction and orientation tuning of RGCs. (a) Example ON direction-selective (DS)-L4 RGC responding to movement of a bar in 12 different directions. Red points show spikes per sweep of the bar in each direction, with spike number plotted as distance from the origin. Below the polar plot are raw spike responses to the preferred and null directions of motion. The bar $(100 \times 200 \mu \mathrm{m})$ was $100 \%$ Weber contrast on a gray background and moved along its long edge at $0.5 \mathrm{~mm} \mathrm{~s}^{-1}$. (b) Same format as (a) for an example ON-OFF DS-L4.5/L7.5 RGC. Two spike bursts are observed for the leading (ON response) and trailing edge of the bar (OFF response). (c) Example of a large bistratified (ON-OFF LB1-L3.5/L8) RGC with mild orientation tuning in response to a grating that drifted in eight different directions. Red points show firing rate (spikes $\mathrm{s}^{-1}$ ) in response to the 6-s presentation of the grating. The grating was presented in a square region (1.6 $\times$ $1.6 \mathrm{~mm}$ ) at $100 \%$ Michelson contrast with a spatial frequency of 5.3 cycles $\mathrm{mm}^{-1}$ and temporal frequency of $1 \mathrm{~Hz}$. (d) Same as (c) for an example of a large bistratified (LB Misc-L3.5/L8) RGC with strong orientation tuning

measured previously at $42 \%$ (ChAT inner) and $75 \%$ (ChAT $\left.{ }_{\text {outer }}\right)$ depth within the IPL (Manookin et al., 2008), and accordingly we aligned the ChAT bands here to L4 and L7.5 (Figure 2c) (Li, Woodfin, Long, \& Fuerst, 2016). We associate each RGC type with the layer of its peak fluorescence. ON cells occupied L3 - 5, and OFF cells occupied L7 - 9; ON-OFF monostratified cells occupied L6, which is the boundary between $\mathrm{ON}$ and OFF bipolar cell terminals (Figure 2c). There were no RGCs with peak stratification in L1 and L10, which align with the nuclear boundaries on either side of the IPL and therefore contain relatively few processes (Manookin et al., 2008). There were also no RGCs with peak stratification in L2, which is presumably occupied to a large extent by rod bipolar terminals (Lee et al., 2003).
For a typical RGC, we first made a loose-patch recording of spike responses to spots of varying diameters. Subsequently, we probed for direction-selectivity using moving bars and drifting gratings (see "Materials and Methods" section). These stimuli helped categorize ON, OFF, and ON-OFF cells as well as identify the well-studied ON and ON-OFF direction-selective (DS) RGCs (Figure 3). Following this initial characterization, we used a second electrode to make a whole-cell recording in response to a contrast-reversing spot stimulus. The spot was $200-\mu \mathrm{m}$ diameter, except for ON Alpha cells, which typically responded poorly to a small stimulus and were instead studied with a larger spot (400 to $600-\mu \mathrm{m}$ diameter). In addition to morphology (Figure 2) and directionand orientation-selective responses (Figure 3), RGCs were grouped 


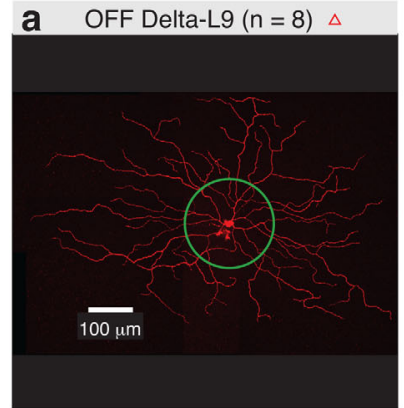

b OFF TS-L8 $(n=2)$

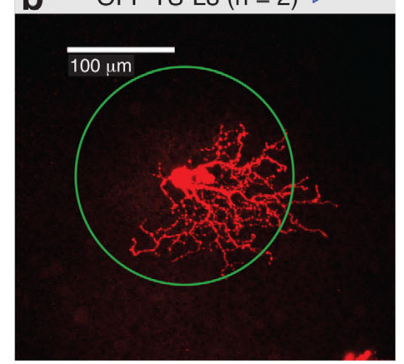

C OFF Misc-L8 $(n=4)$
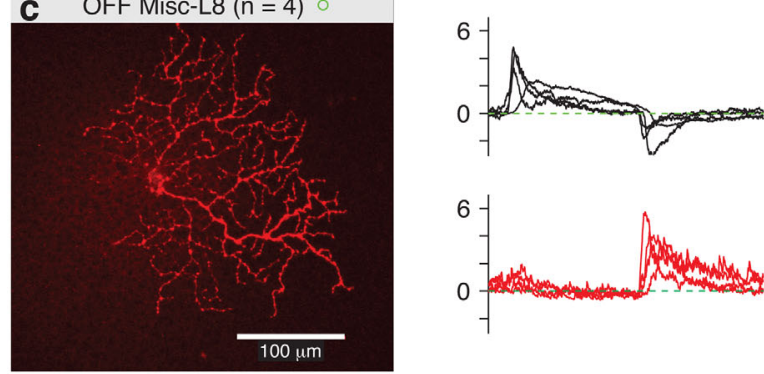

g
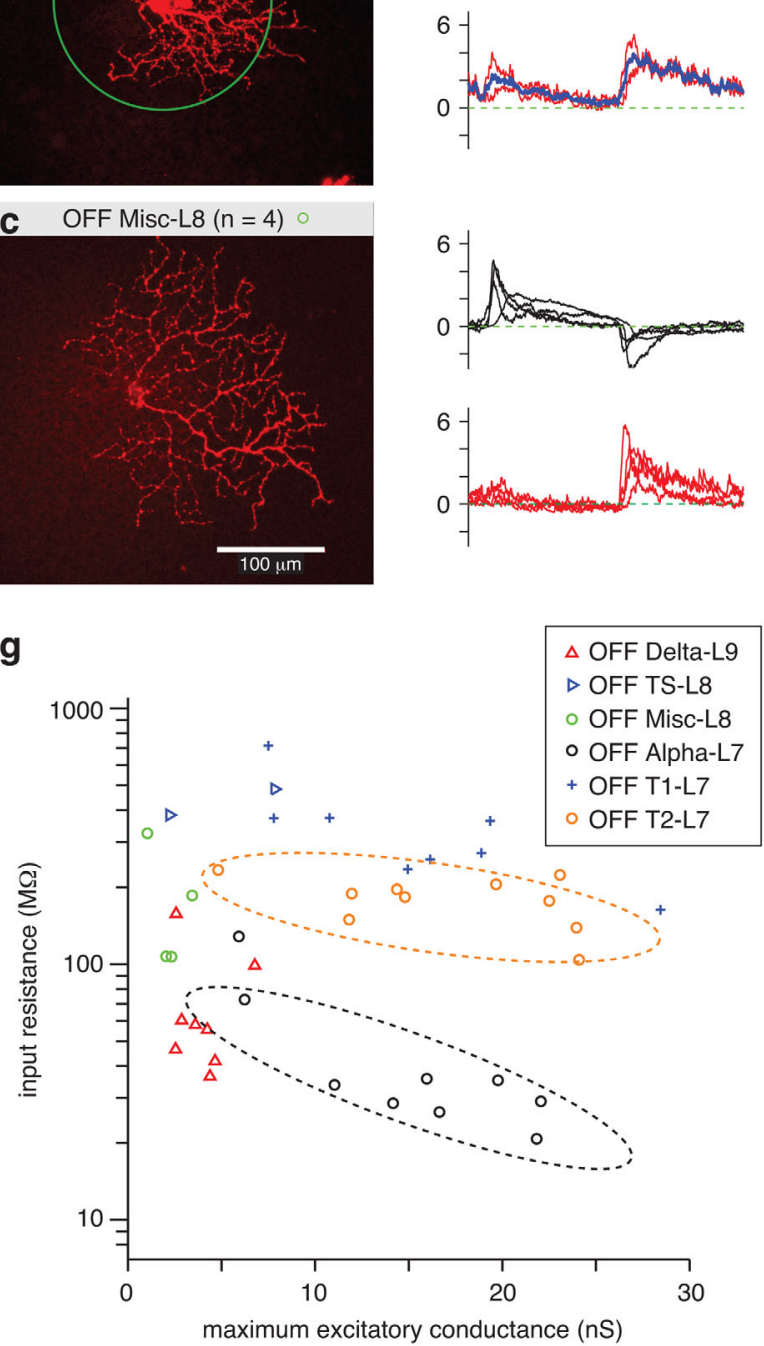
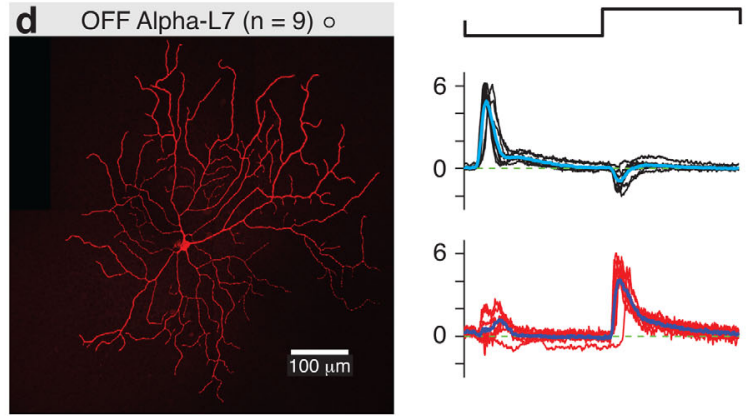

e $\operatorname{OFFT1-L7}(\mathrm{n}=8)$
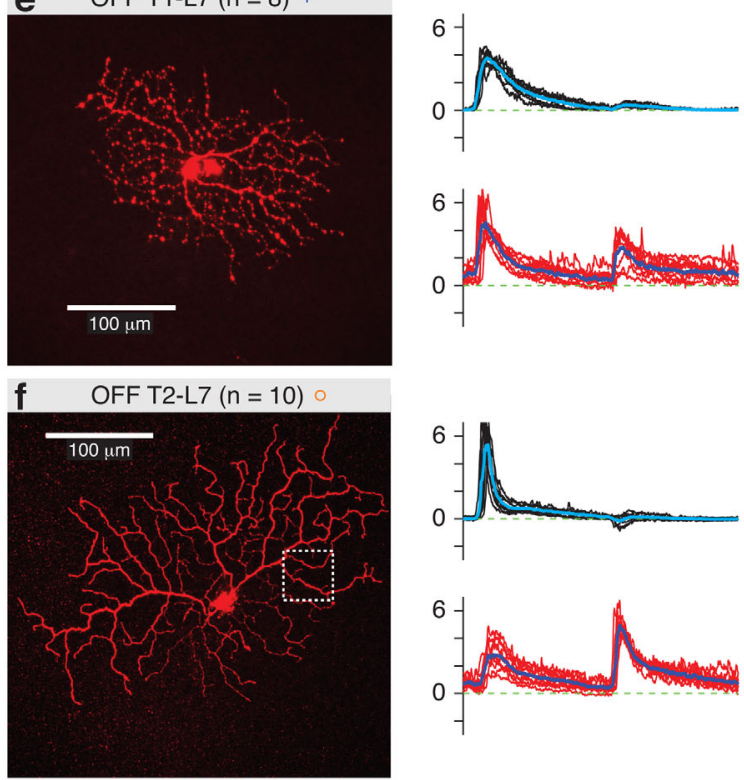

h
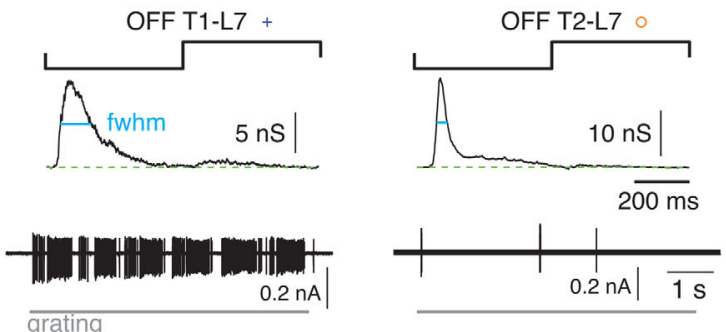

i

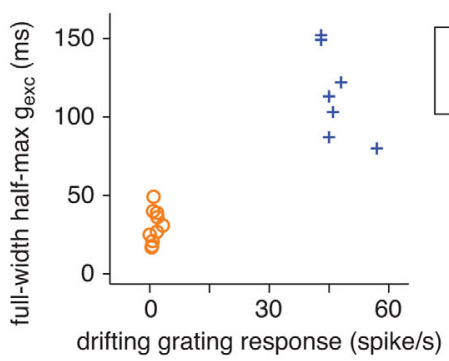

FIGURE 4 OFF RGC types distinguished by spot response and input resistance. (a) Left, an example OFF Delta-L9 RGC filled with Lucifer Yellow superimposed with a green circle representing the contrast-reversing spot stimulus $(0.2-\mathrm{mm}$ diameter, $1 \mathrm{~Hz})$. For the sample of cells $(n=8)$, the normalized (norm.) excitatory (exc.) and inhibitory (inh.) conductances are shown in black and red, respectively, for each cell. The response was normalized by dividing by the SD of the trace. The average response across cells is shown in cyan (excitatory conductance) or blue (inhibitory conductance). (b) Same format as (a) for OFF TS-L8 cells. This cell is shown with the 0.2-mm diameter spot superimposed. (c) Same format as (a) for OFF Misc-L8 cells. (d) Same format as (a) for OFF Alpha-L7 cells. (e) Same format as (a) for OFF T1-L7 cells. (f) Same format as (a) for OFF T2-L7 cells. The boxed area indicates the region of interest shown as a side projection in Figure $2 \mathrm{a}$. (g) Input resistance $\left(R_{\text {in }}\right)$ plotted against maximum excitatory conductance for OFF cells of all types show in a-f. $R_{\text {in }}$ distinguished certain cell types. For example, $R_{\text {in }}$ of OFF Alpha-L7 cells (dashed black line) was lower than for OFF T2-L7 cells (dashed orange line), even though their dendrites co-stratified (Figure 2c). (h) Excitatory conductance and spike responses distinguished OFF T1-L7 and OFF T2-L7 RGCs. The fullwidth at half-maximum (fwhm) of the excitatory conductance was measured during the OFF response (cyan line). The spike rate was measured to the drifting grating stimulus (see Figure 3). (i) OFF T1-L7 cells had a relatively longer fwhm of excitatory conductance ( $g_{\text {exc }}$ ) and a higher firing rate to the grating 

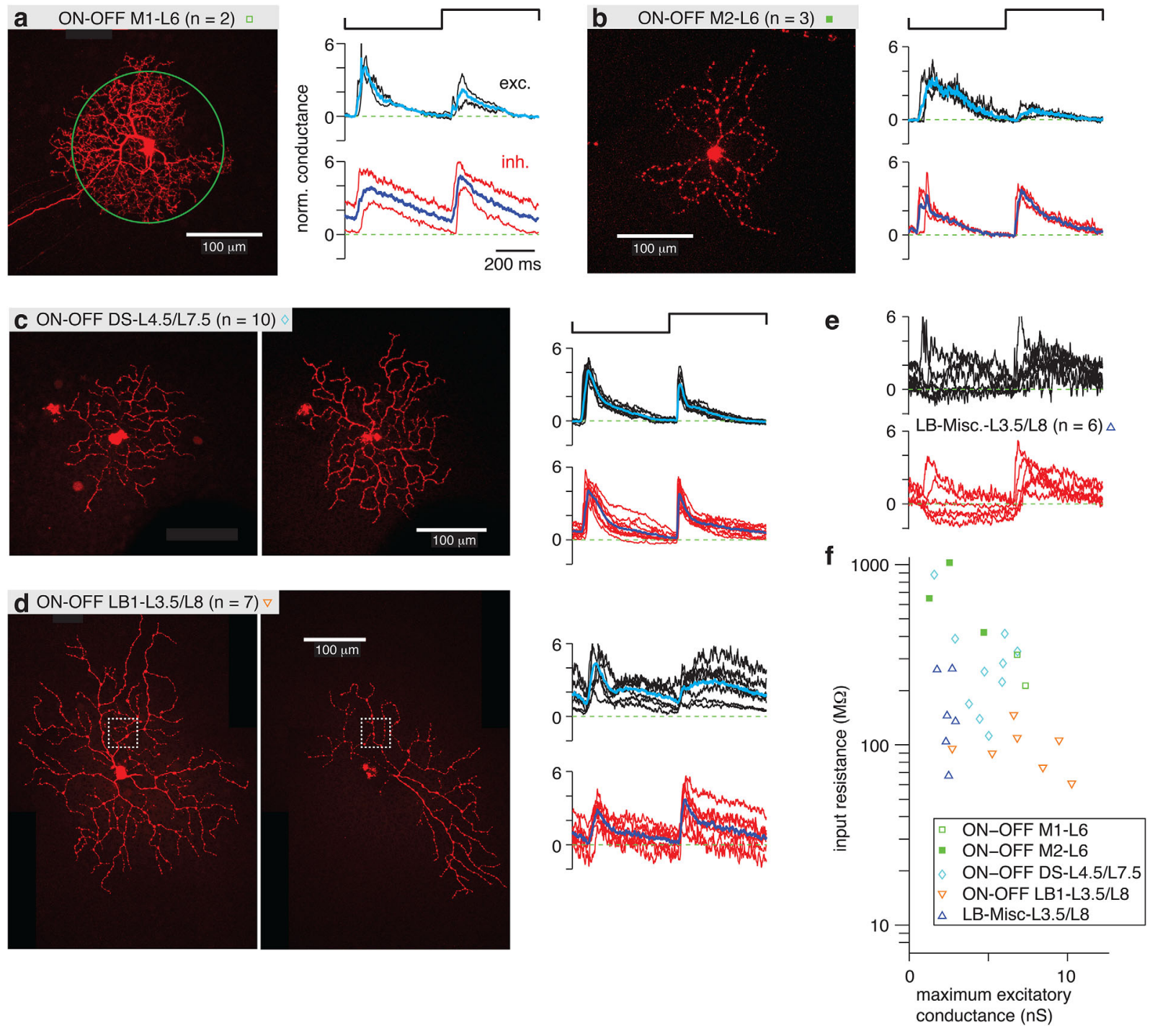

FIGURE 5 ON-OFF RGC types distinguished by spot response and input resistance. (a) Left, an example ON-OFF M1-L6 RGC filled with Lucifer Yellow superimposed with a green circle representing the contrast-reversing spot stimulus (0.2-mm diameter, $1 \mathrm{~Hz})$. Normalized (norm.) excitatory (exc.) and inhibitory (inh.) conductances are shown for each cell, as in Figure 4. The average response across cells is shown in cyan (excitatory conductance) or blue (inhibitory conductance). (b) Same format as (a) for ON-OFF M2-L6 cells. (c) Same format as (a) for ON-OFF DS-L4.5/L7.5 cells. Both inner (left) and outer (right) dendrites are shown. (d) Same format as (c) for ON-OFF LB1-L3.5/L8 cells. The boxed area indicates the region of interest shown as a side projection in Figure $2 \mathrm{~b}$. (e) Normalized conductances for a group of miscellaneous large bistratified cells (LB-Misc) that stratified in L3.5 and L8. (f) The $R_{\text {in }}$ for ON-OFF M1-L6 cells was the highest of all groups, whereas the ON-OFF LB1-L3.5/L8 cells had the lowest $R_{\text {in }}$

primarily by the time course of their excitatory conductance to the contrast-reversing spot stimulus (Figures 4-6). In some cases, cells were further distinguished by their input resistance $\left(R_{\text {in }}\right)$, which was calculated from the baseline currents measured at two holding potentials within $20 \mathrm{mV}$ of the resting potential (Figures 4-6).

\section{1 | OFF cells}

The OFF RGC types stratified between L7 and L9 (Figure 2c). L9 contained the well-studied OFF Delta cell (OFF Delta-L9) defined partly by its large soma, which was used to target these cells, as well as its wide dendritic field (Homann \& Freed, 2017; Manookin et al., 2008; Figure 2c). OFF Delta cells had sustained excitatory conductance to light offset (Figure 4a) and a relatively low $R_{\text {in }}(<100 \mathrm{M} \Omega$ in most cases; Figure $4 \mathrm{~g})$. The excitatory and inhibitory conductances to the spot stimulus are shown in normalized coordinates (i.e., the response divided by its $S D$; Figure 4a). The maximum excitatory conductance for each cell is also plotted relative to its $R_{\text {in }}$ (Figure $4 \mathrm{~g}$ ).

We also encountered, though rarely, an OFF Transient-Sustained type (OFF TS-L8; Figure 4b) that stratified in L8 and could be distinguished from the OFF Delta cell based on its smaller soma size, smaller dendritic tree (Figure 2c) and higher $R_{\text {in }}$ (Figure 4g). An additional group of miscellaneous cells (OFF Misc-L8) could likewise be distinguished from OFF Delta cells based on smaller soma size, smaller dendritic tree 

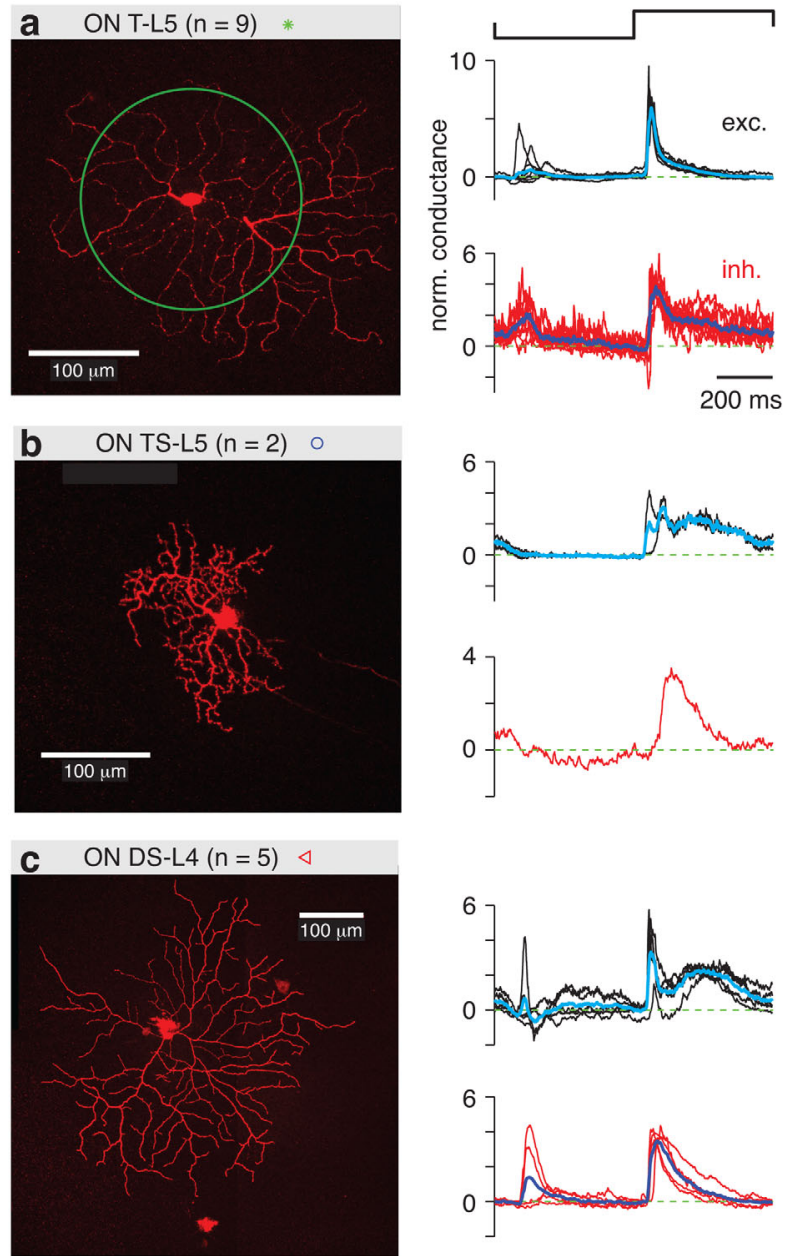
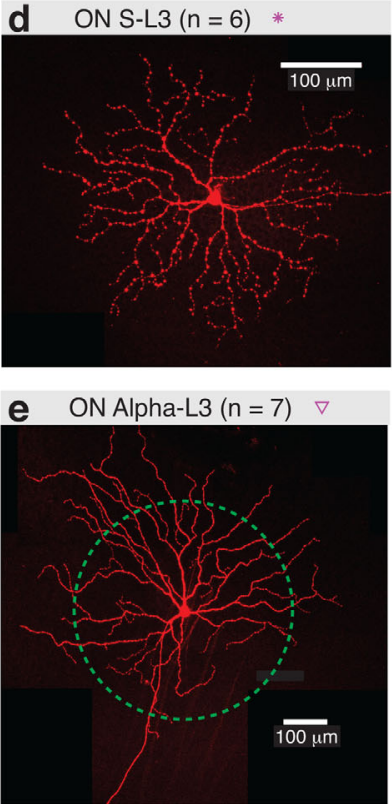
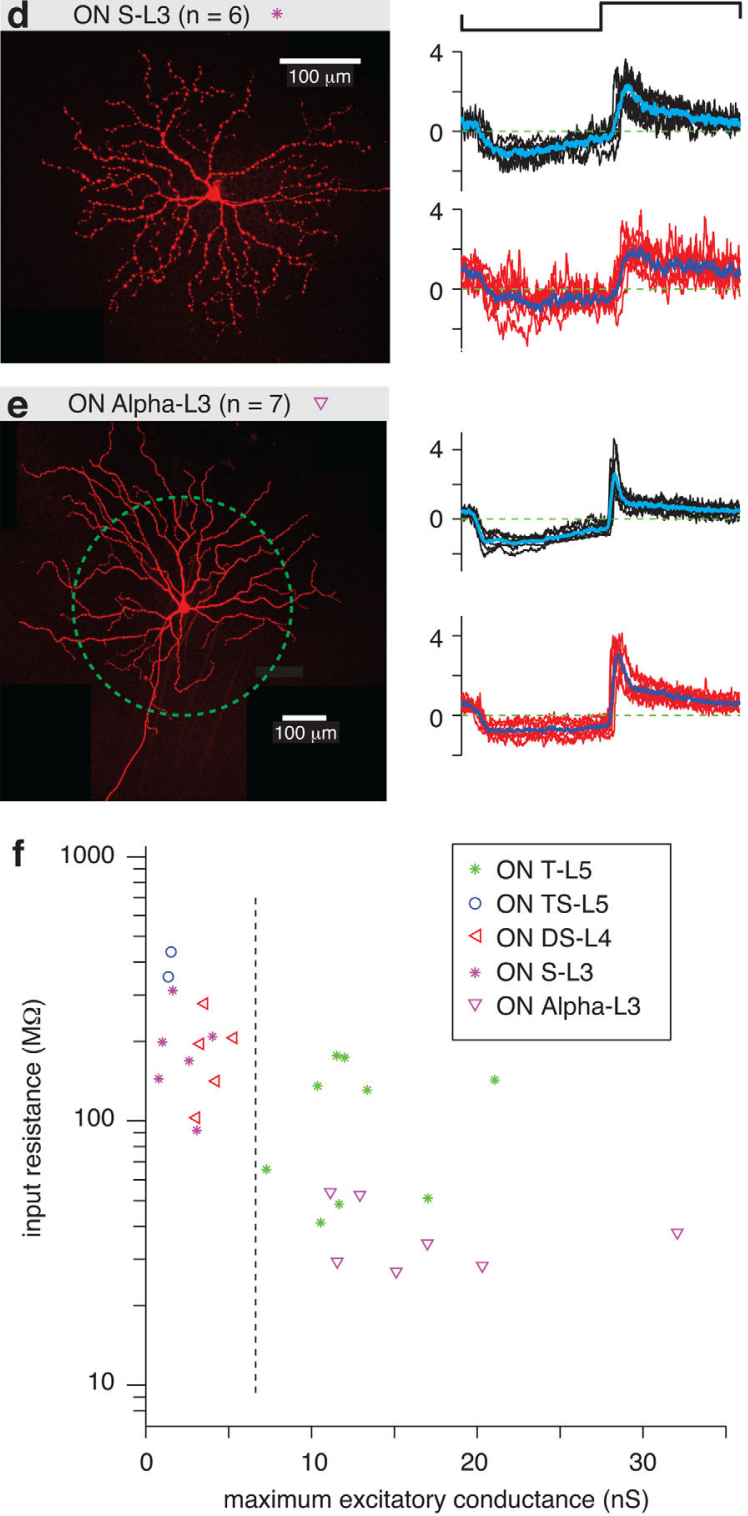

FIGURE 6 ON RGC types distinguished by spot response and input resistance. (a) Left, an example ON T-L5 RGC filled with Lucifer Yellow superimposed with a green circle representing the contrast-reversing spot stimulus (0.2-mm diameter, $1 \mathrm{~Hz}$ ). Normalized (norm.) excitatory (exc.) and inhibitory (inh.) conductances are shown for each cell, as in Figure 4. The average response across cells is shown in cyan (excitatory conductance) or blue (inhibitory conductance). (b) Same format as (a) for ON TS-L5 cells. Inhibition was measured in only one case. (c) Same format as (a) for ON DS-L4 cells. (d) Same format as (a) for ON S-L3 cells. (e) Same format as (a) for ON Alpha-L3 cells. For these cells, a large spot size was used (0.5- $\mathrm{mm}$ diameter, dashed green line). (f) $R_{\text {in }}$ and maximum excitatory conductance distinguished certain cell types. For example, ON T-L5 and ON Alpha-L3 cells had a relatively larger maximum conductance than the other types, which could be separated by the dashed line. ON S-L3 and ON Alpha-L3 co-stratified (Figure 2c), but ON Alpha-L3 cells had lower $R_{\text {in }}$

size (Figure $2 \mathrm{c}$ ) and higher $R_{\text {in }}$ (Figure $4 \mathrm{~g}$ ). These OFF Misc-L8 cells may include more than one type but were not divided further based on the available data (Figure 4c).

L7 contained three RGC types (Figure 2), including the familiar OFF Alpha cell (OFF Alpha-L7) defined partly by its large soma used to target these cells, as well as its wide dendritic tree (Beaudoin et al., 2007; Demb et al., 2001; Manookin et al., 2008; Figure 2c). OFF Alpha cells had relatively transient light responses to negative contrast (Figure $4 d$ ) and relatively low $R_{\text {in }}(<100 \mathrm{M} \Omega$ in most cases; Figure $4 \mathrm{~g})$. Two other RGC types co-stratified with OFF Alpha cells, which we refer to as OFF Transient types 1 and 2 (OFF T1-L7, OFF T2-L7; Figure 4e,f). OFF T1 and T2 cells could be distinguished from OFF Alpha cells based on smaller dendritic trees (Figure $2 \mathrm{c}$ ) and relatively higher $R_{\text {in }}(>100$ $\mathrm{M} \Omega$ in most cases; Figure 4g). OFF T1 and T2 cells could be further distinguished from one another based on two measured properties. OFF T1 cells had a relatively extended time course of excitatory conductance at negative contrast, defined by the full-width at half-maximum (fwhm) of the OFF response (Figure 4h). The OFF T1 cells also had a 
robust spike response to a drifting grating stimulus ( 5.3 cycles $\mathrm{mm}^{-1}, 1$ $\mathrm{Hz}$ ), which was not sensitive to direction (Figure 4h). Based on these properties, the sample of OFF T1 and T2 cells fell into two distinct groups (Figure 4i). OFF T1 cells also tended to have a higher $R_{\text {in }}$ than OFF T2 cells (Figure 4g).

\section{2 | ON-OFF cells}

The ON-OFF RGC types comprised monostratified cells in L6 and bistratified cells either in L4.5/L7.5 or L3.5/L8 (Figure 2c). Monostratified cells stratified in the middle of the ChAT bands with relatively small receptive fields (Figure 2c). Within this group of monostratified (M) cells, there were two types distinguished by the density of their dendritic tree. The ON-OFF M1-L6 cells were denser than the ON-OFF M2L6 cells (Figure 5a,b). There were corresponding differences in the time-course of excitatory conductance (Figure $5 \mathrm{a}, \mathrm{b}$ ) and a relatively higher $R_{\text {in }}$ for ON-OFF M2 cells (Figure 5 f).

The bistratified ON-OFF cells included the well-studied ON-OFF direction-selective cell (ON-OFF DS-L4.5/L7.5), which co-stratifies with the ChAT bands (Figure 2c) and has a characteristic transient ONOFF response (Figure $5 \mathrm{c}$ ). These cells showed the familiar direction selectivity to a drifting bar stimulus (Figure $3 b$ ). The other bistratified cells projected dendrites into layers that bracketed the ChAT bands and had relatively larger dendritic tree diameters, especially within the ON layer (L3.5; Figure 2c). For one group of large bistratified cells (ONOFF LB1-L3.5/L8), there was a consistent pattern of sustained ON and OFF response (Figure $5 \mathrm{~d}$ ) with a relatively low $R_{\text {in }}$ of $\sim 100 \mathrm{M} \Omega$ (Figure 5f). A miscellaneous group of large bistratified cells (LB-Misc-L3.5/L8) showed varying degrees of ON and OFF response in the excitatory conductance (Figure 5e). Some of these cells showed strong orientation selectivity to a drifting grating stimulus (Figure 3d), whereas ON-OFF LB1 cells typically showed weaker orientation selectivity at most (Figure 3c); and neither group of LB cell showed direction selectivity. The LB-Misc group apparently included more than one type, but the group was not further distinguished based on the available data.

\section{3 | ON cells}

The ON RGC types stratified in L3 - 5 (Figure 2). Cells in L5 included a highly transient type (ON T-L5; Figure 6a) and a more rarely encountered type with both transient and sustained response components (ON TS-L5; Figure 6b). These types could be distinguished from one another based on the lower $R_{\text {in }}$ for ON T-L5 cells (Figure 6f). Cells in L4 were the familiar ON DS cells (Figure 6c), which showed direction selectivity to a drifting bar stimulus (Figure 3a). Cells in L3 included the familiar ON Alpha cell (Beaudoin et al., 2007; Demb et al., 2001; Manookin et al., 2008; Figure 6e), with its large soma, wide dendritic field (Figure $2 \mathrm{c}$ ) and relatively low $R_{\text {in }}$ (Figure 6f). By contrast, ON S-L3 cells were relatively more sustained (Figure $6 \mathrm{~d}$ ) and had smaller dendritic fields (Figure 2c) and higher $R_{\text {in }}$ (Figure 6f).

The cell types defined above were sorted manually using the combination of morphological parameters (dendritic tree diameter, stratification), direction selectivity of the spike response, the pattern of excitatory conductance and the $R_{\mathrm{in}}$. This resulted in 16 groups, although the two miscellaneous groups likely include more than one type in each. Furthermore, the opportunity for a direct glycinergic input from the All likely only occurs for those types that stratify some of their dendrites within the OFF regions of the IPL, L6 - 9. If the All did make a connection to a RGC type, it would be expected to provide inhibition at light onset, a conductance that was notably observed in every cell type studied (Figures 4-6).

\subsection{Evaluating All connections across cell types}

We examined All connections by measuring inhibitory conductance at light onset with iGluRs blocked ( $n=77$ cells). This response should depend on the All circuit, which can convey glycinergic inhibition to RGCs in the absence of functioning iGluRs (Figure 1c). The iGluRs were blocked with a combination of an AMPA/kainate receptor antagonist (200 $\mu$ M CNQX or $100 \mu$ M DNQX) and an NMDA receptor antagonist (100 $\mu$ M D-AP5; Manookin et al., 2008, 2010). The response to the spot stimulus was recorded for both excitatory and inhibitory conductances in each cell type before and after adding the drugs.

Three cell types showed a persistent inhibitory conductance during iGluR block. This included the OFF Alpha cell, shown to respond under this condition previously (Beaudoin et al., 2008; Manookin et al., 2008) as well as OFF Delta-L9 and OFF T2-L7 cells. In some cases, we obtained a wash recording after removing the drug and observed a partial recovery of the original conductances measured under the control condition (Figure 7a). By contrast, other cell types showed a complete block of both excitatory and inhibitory conductances in the presence of iGluR block. This included OFF and ON-OFF cell types that either stratified near OFF Alpha and Delta cells (e.g., OFF T1-L7, OFF TS-L8, ON-OFF LB-L3.5/L8) or stratified between these levels (e.g., ON-OFF DS-L4.5/L7.5; Figure 7b).

A population analysis demonstrated the profound block of excitatory conductance in the presence of iGluR block, as expected (Figure 8a). The inhibitory conductance was likewise blocked in all cases except for the three OFF RGC types noted above (Figure 8b). For each of these cell types, the drug-resistant inhibitory conductance (drug:control; Figure 8c) was significantly greater than zero (one-tailed $t$ test): OFF Delta-L9, $p=.0036$ (one outlier removed); OFF Alpha-L7, $p=.0038$ (one outlier removed); OFF T2-L7, $p=.0035$. The drugresistant inhibitory conductance was similar for OFF Delta-L9 and OFF Alpha-L7 cells (two-tailed $t$ test, $p=.13$ ) but was significantly greater for OFF Delta-L9 cells compared to OFF T2-L7 cells $(p=.0048)$ and for OFF Alpha-L7 cells compared to OFF T2-L7 cells $(p=.016)$. Because we did not obtain a wash recording in each case, we assessed recording integrity across the population of RGCs by comparing $R_{\text {in }}$ in the control and the drug condition. $R_{\text {in }}$ changed by less than a factor of two between the control and drug conditions for $89.5 \%$ of cells, suggesting that recording integrity was relatively intact during the drug condition, when the visual response was eliminated in most cases (Figure $8 d$ ). On average, $R_{\text {in }}$ increased by $22.7+/-5.4 \%$ in the drug condition, relative to control, consistent with the closing of ligand-gated channels in the cell membrane. 
a
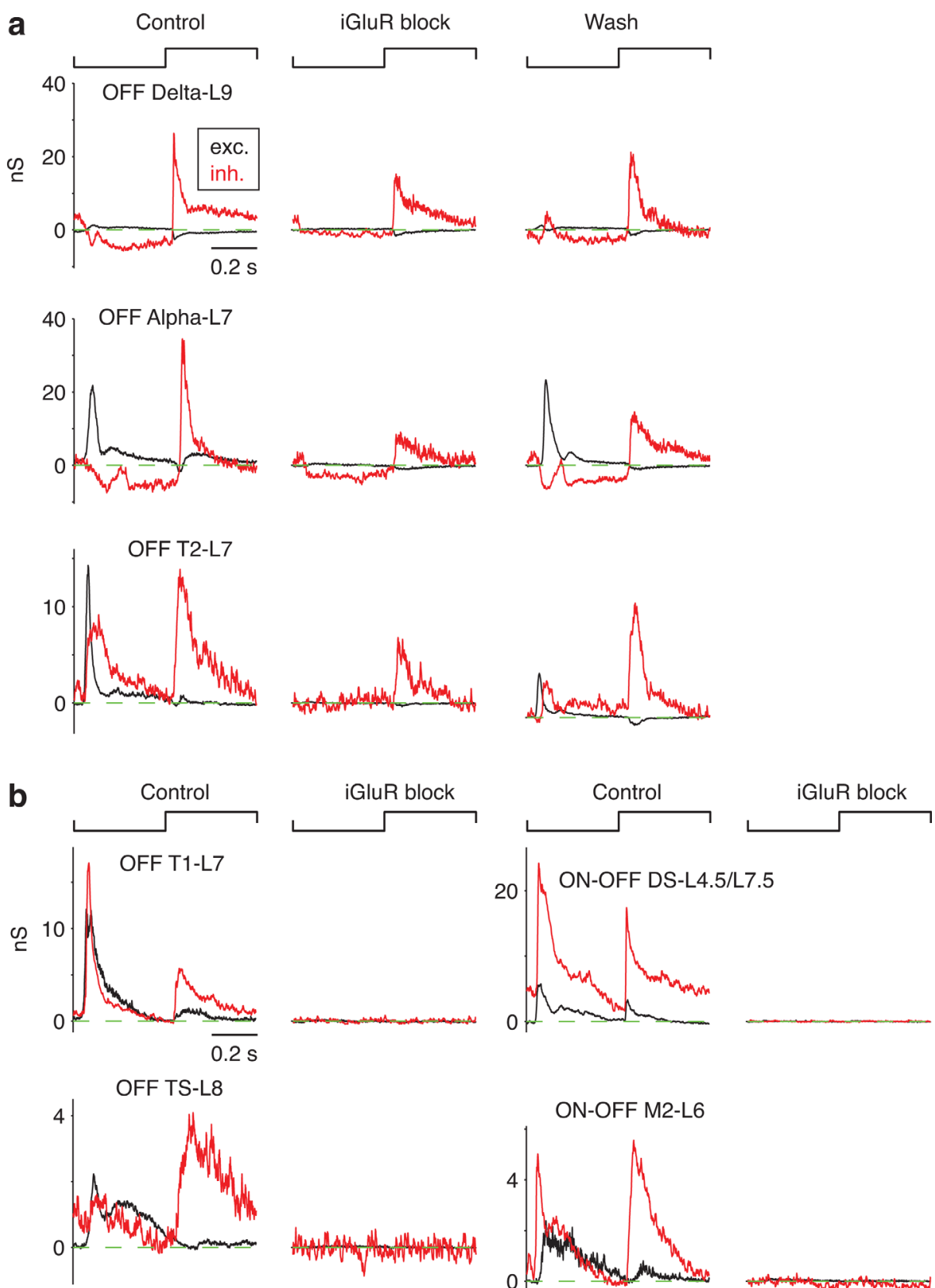

ON T-L5
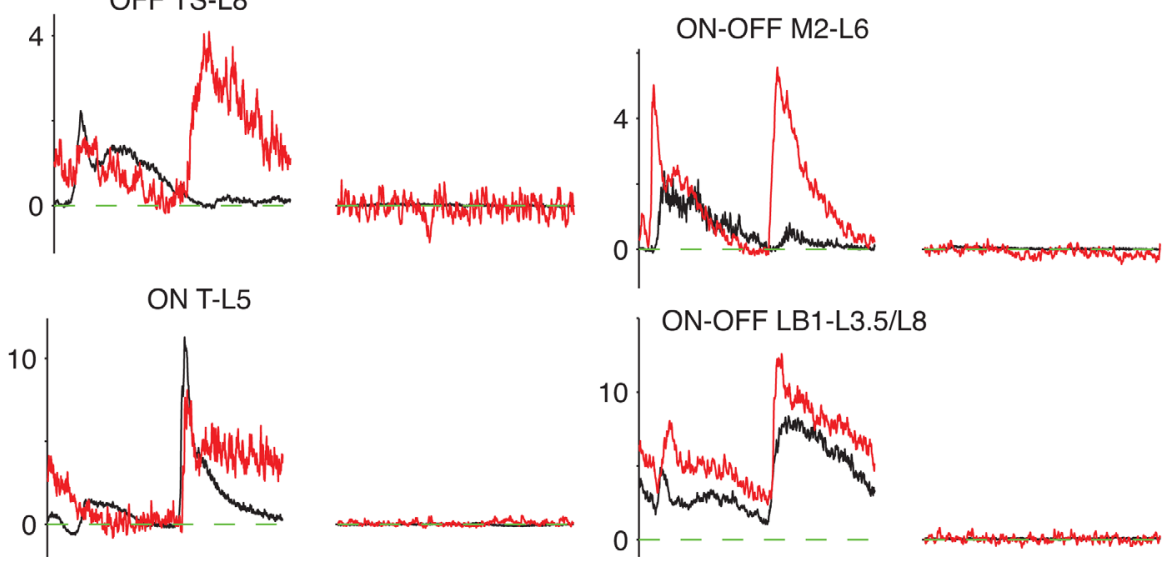

FIGURE 7 All amacrine cells make synapses with three OFF RGC types. (a) The excitatory (exc.) and inhibitory (inh.) conductance to a contrast-reversing spot (0.2-mm diameter) before (Control), during (iGlur block) and after (Wash) bath-applying iGluR antagonists (either $200 \mu \mathrm{M}$ CNQX or $100 \mu \mathrm{M}$ DNQX with $100 \mu \mathrm{M}$ D-AP5). For three OFF RGC types (OFF Delta-L9, OFF Alpha-L7, and OFF T2-L7), the inhibitory conductance persisted following iGluR block. A partial recovery was observed in the Wash condition. (b) Examples of other RGC types that lacked any sign of a light-driven conductance following iGluR block

Assuming the persistent inhibitory conductance in the three OFF types with iGluR block came from the same source, namely the All amacrine cell, the time course of the postsynaptic conductance should be very similar. We examined this by plotting the average, normalized inhibitory conductance for OFF Delta cells $(n=8)$, OFF Alpha cells $(n=8)$ and a subset of OFF T2-L7 cells that showed a qualitatively 
a
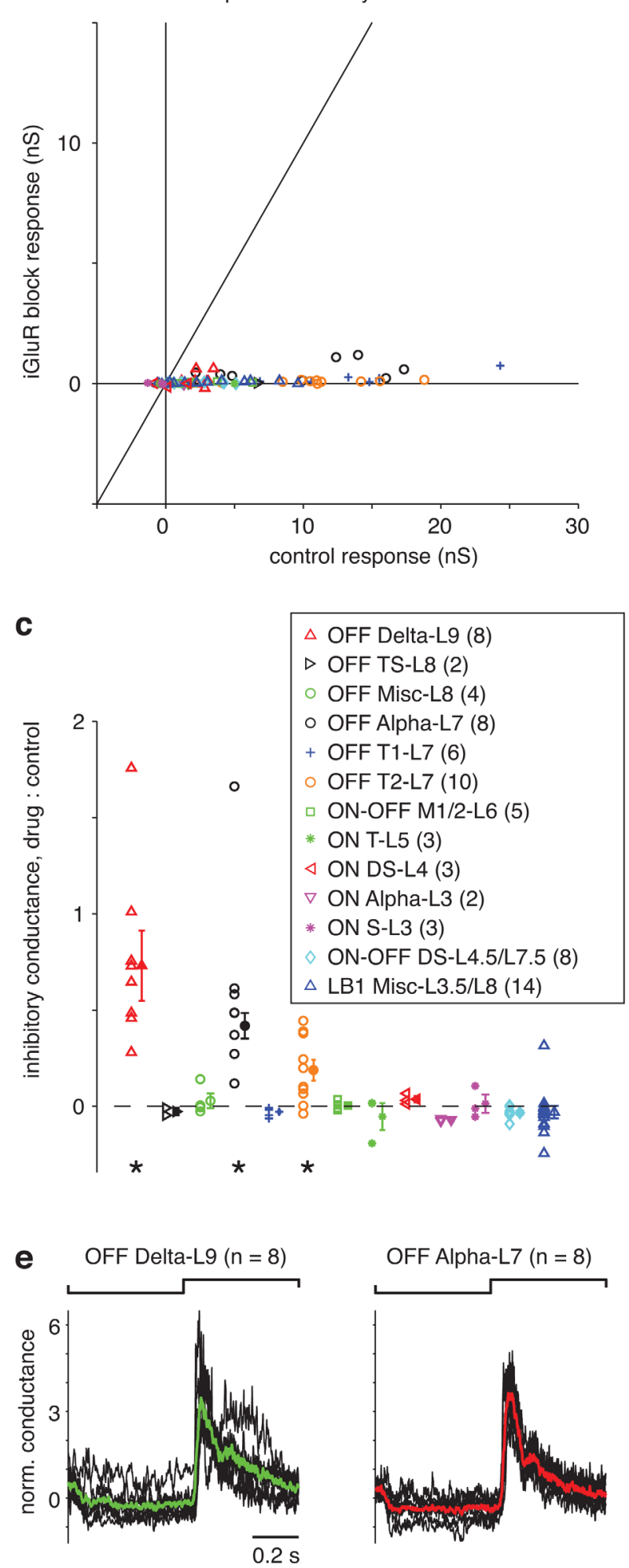

b

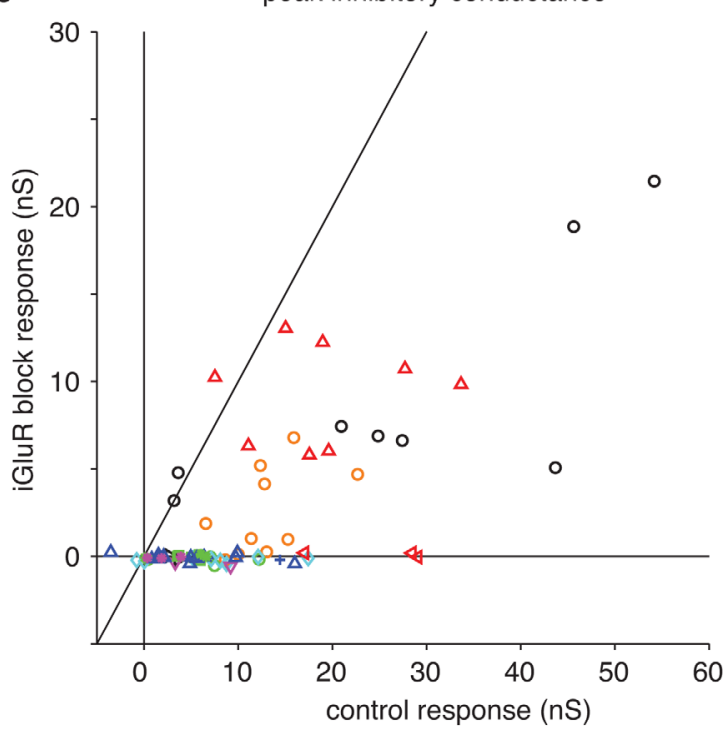

d
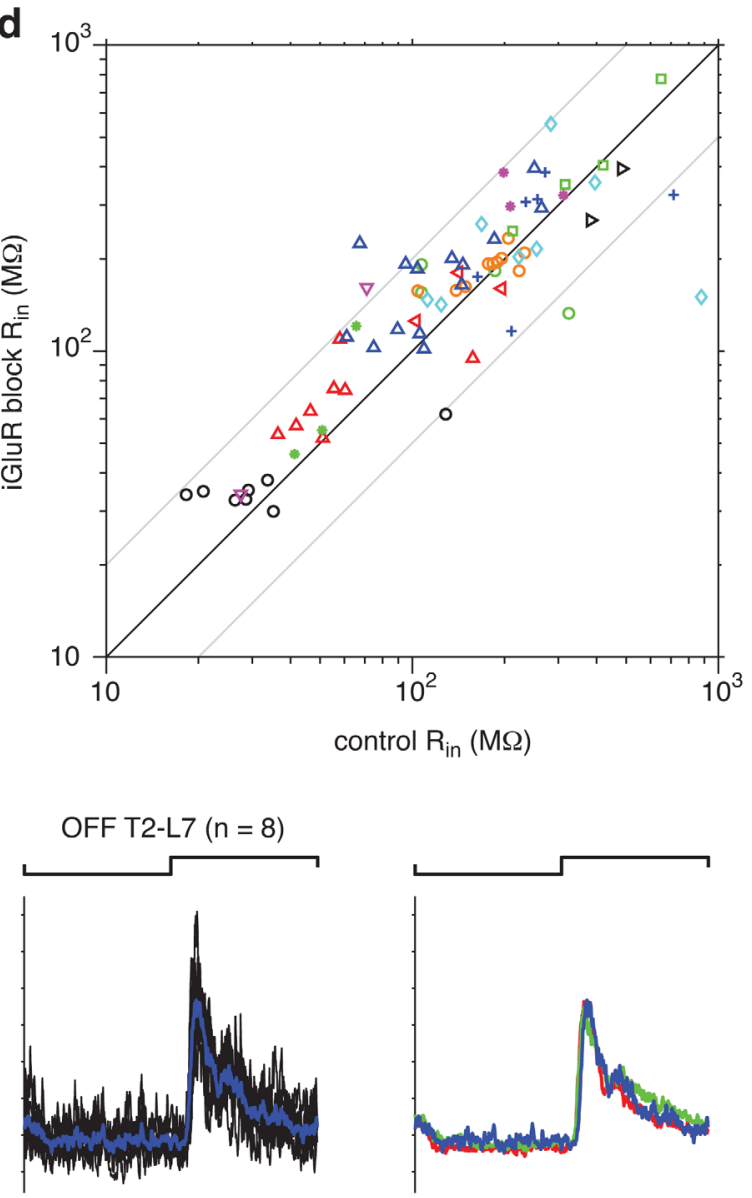

FIGURE 8 Population analysis shows that All amacrine cells make synapses with a privileged minority of RGC types. (a) The peak excitatory conductance measured for control versus iGluR block conditions. The response for each cell was averaged over a 30-ms time window centered on the peak excitatory conductance for the control condition. Responses of all cell types were strongly suppressed, as expected. Symbols for each cell type are shown in c. The identity line is shown here and in b. (b) Same format as (a) for the inhibitory conductance. Data for three cell types show a persistent response under iGluR block. (c) The inhibitory conductance measured under iGluR block relative to the control condition shows a significant response $(p<.05)$ for three OFF RGC types (*; with the large outlier removed for both OFF Delta-L9 and OFF Alpha-L7 cells). Conductance was averaged over a 150-ms time window, 50-ms following light onset. Some cell types were grouped for this analysis and in a, b, and d: ON-OFF M1 and M2 cells; and ONOFF LB1-L3.5/L8 and LB-Misc-L3.5/L8 cells. (d) The $R_{\text {in }}$ was relatively stable between control and iGluR block conditions, changing by less than a factor of two (i.e., points between the gray diagonal lines) for $\sim 89 \%$ of cells. (e) For three OFF RGC types, the inhibitory conductance under iGluR block showed a common temporal profile. For each RGC type, black lines show the normalized (norm.) inhibitory conductance during contrast reversal. Colored lines show the average for the group, which are shown superimposed at right 
discernable response by eye ( $n=8$ of 10 cells). The average time course for these groups was nearly identical, consistent with a single source for inhibition across the three cell types (Figure 8e). The average traces indicated two response components, an initial transient after light onset followed by a secondary peak $\sim 200$ ms later. These components may depend differentially on cone versus rod inputs, but the mechanism was not studied further here.

\section{4 | DISCUSSION}

\section{1 | All amacrine cells connect selectively to specific RGC types}

The main finding from this study is that All amacrine cells make direct synaptic connections with a privileged minority of RGC types. The All cell in guinea pig, as in other mammals, has lobular appendages with glycine release sites in the OFF layers (L6 - 10; Figure 2c) of the IPL (Demb \& Singer, 2012; Lee et al., 2003). Of the RGC types studied here, at least 11 had the potential for a contact with the All-this included monostratified and bistratified cells with either OFF or ON-OFF excitatory conductance, implicating a costratification with OFF cone bipolar terminals which themselves costratify with All lobular appendages (Demb \& Singer, 2012). There were also five types of ON RGC that stratified in L3 - 5 that served as a control. Of the 11 OFF or ON-OFF RGC types, only three received a direct input from the All according to our functional assay, including OFF Delta-L9, OFF Alpha-L7, and OFF T2-L7 types (Figures 7 and 8). Many of the types that were not connected stratified in the same layer or an adjacent layer with the types that were connected (Figures $2 c$ and 8). For example, in the case of OFF T1-L7 RGCs, there was remarkable similarity in dendritic field size and stratification to the connected type OFF T2-L7 (Figure 2c). Yet, the presumed All inputs were made to OFF T2 but not OFF T1 cells (Figures 7 and 8). Some of the other unconnected RGC types, including OFF TS-L8 cells $(n=2)$, were recorded more rarely; but even in these cases there was no hint of any inhibitory conductance in the presence of iGluR blockers to implicate an All connection (Figure 7b).

Our physiological results align with EM reconstruction of the All network in rabbit, which suggested that RGC dendrites, of unknown types, commonly contact All lobules at locations that lack synaptic specializations. The exceptions were dendrites of specific RGC types, including OFF Alpha and Delta cells, which made synaptic contacts (Marc et al., 2014). All amacrine cell connections are apparently highly precise and specific to RGC type. This seems to be an example where simple rules based on co-stratification do not predict the precision of actual connections within a neural circuit (Peter's rule; Krishnaswamy, Yamagata, Duan, Hong, \& Sanes, 2015; Park et al., 2015; Peters \& Feldman, 1976; Stepanyants \& Chklovskii, 2005).

Our evidence for an All $\rightarrow$ RGC connection relied on a functional assay, where postsynaptic inhibitory conductance persisted in the presence of iGluR blockers. The apparent mechanism for the persistent response depends on the following circuit: rod/cone $\rightarrow$ ON cone bipolar $\rightarrow$ All $\rightarrow$ OFF-layer RGC dendrite (Figure 1c). This assumption is supported by several findings. First, the persistent response in iGluR blockers was sensitive to blocking the ON pathway, gap junctions and glycine receptors, which can collectively be explained by the remaining synapses in the All circuit (Figure 1c; Bloomfield, Xin, \& Osborne, 1997; Liang \& Freed, 2010; Manookin et al., 2008; Münch et al., 2009; Murphy \& Rieke, 2008). Second, the OFF Alpha cell, which responds with an inhibitory conductance in the presence of iGluR blockers, was shown to receive a direct All input via an independent method, paired whole-cell recordings (Münch et al., 2009; Murphy \& Rieke, 2008). Third, the persistent response in iGluR blockers studied here showed a nearly identical time course in three different RGC types, implicating a common presynaptic mechanism (Figure 8e). Interestingly, the five ON RGC types studied here showed no inhibitory conductance with iGluR block, suggesting that there is not widespread electrical input from ON cone bipolar cells to amacrine cells, which would otherwise maintain intact inhibition following iGluR block. This apparently differs from the mouse retina, where an ON RGC did receive an inhibitory input following iGluR block (Farrow et al., 2013).

\subsection{Identifying cell types in the guinea pig retina}

To investigate specific connections in retinal circuitry, it is necessary to identify the component parts, that is, the cell types. In the mouse retina, it is now possible to label many of the types using transgenic lines (Sanes \& Masland, 2015), whereas in the guinea pig it is necessary to collect signature morphological and physiological properties that define the types. There was a clear advantage to quantitatively measuring dendrite stratification relative to the ChAT bands, which immediately divides the cells into discrete groups. This analysis was supplemented by measurements of excitatory conductance, $R_{\mathrm{in}}$, and responses to moving stimuli, which further divided the RGCs into at least 16 types (Figures 2-6). In the mouse, there is evidence for roughly twice this many types (Baden et al., 2016), and the guinea pig likely shows the same level of cell type diversity. Thus, there are apparently more types than we identified here, and at least some of these additional types may also receive direct synapses from the All.

Previous studies of guinea pig retina identified $\sim 10$ RGC types (Freed \& Liang, 2010). This included the three types with large soma (ON Alpha, OFF Alpha, OFF Delta) as well as the ON DS cell (ON Delta). The G5 RGC identified in another study received a presumed input from the All, because its inhibitory conductance was suppressed by a gap junction blocker (Liang \& Freed, 2010). The G5 cell likely corresponds to the OFF T2-L7 cell in the current study, but the correspondence between other types is not entirely clear. Our study had the advantage of measuring stratification in fixed tissue relative to the ChAT bands in every RGC, which could facilitate the ability to match RGC types across laboratories in the future. Interestingly, the plot of stratification versus dendritic tree size in guinea pig (Figure $2 \mathrm{c}$ ) resembles a similar plot in the mouse retina for parvalbumin-expressing RGCs, suggesting some correspondence between species on RGC-type properties based on the two morphological dimensions (Farrow et al., 2013). 


\section{3 | Functional implications for a direct synaptic input from the All amacrine cell}

The sparseness of All-RGC connections might seem surprising given the potential benefit for visual function. For example, there would seem to be an advantage of RGCs connecting to the night vision pathway to extend their function in dim light; and there could possibly be some advantage, for OFF or ON-OFF cells, to having a direct input from the All rather than signaling through OFF cone bipolar terminals. Indeed, in the mouse retina, there is evidence that the most sensitive rod signals are conveyed more efficiently through direct glycinergic synapses with RGCs as compared to a pathway through OFF bipolar cell terminals (Arman \& Sampath, 2012). In human, melanopsin-expressing RGCs may be among the types connected to the All (Hannibal, Christiansen, Heegaard, Fahrenkrug, \& Kiilgaard, 2017). In a nocturnal mammal, such as mouse, All connections may follow the same rule as in guinea pig and contact only a minority of RGC types. This includes OFF Alpha and Delta RGC types, whose physiology and dendrite stratification matches properties found in guinea pig (Margolis \& Detwiler, 2007; Münch et al., 2009; Murphy \& Rieke, 2006, 2008; van Wyk et al., 2009). It also apparently includes SbC RGCs in mouse (Jacoby et al., 2015). OFF beta RGCs in cat apparently receive an All input (Cohen, 1998; Kolb \& Nelson, 1993), whereas OFF sustained RGCs in rabbit apparently do not (Buldyrev, Puthussery, \& Taylor, 2012). Interestingly, small bistratified cells in primates lose their OFF response but retain an ON response in dim light, suggesting that the All cell contributes to sensitive night vision responses in some ON-OFF cells exclusively through the ON pathway (Field et al., 2009). Therefore, some OFF pathway cells in the retina may decrease their function in dim light. In summary, the indirect pathway for All signals (All $\rightarrow$ cone bipolar terminal $\rightarrow$ RGC) likely contributes to highly sensitive rod vision for the ON system; whereas for the OFF system, there may be some advantage to the direct connection between the All and the RGC. Further studies will be required to determine how direct versus indirect connections between the All and different RGC types corresponds to absolute differences in visual sensitivity.

There are several additional roles that a direct All synapse could play in visual processing. These include a possible mechanism for feedforward inhibition at light offset, since the All lobular appendages receive a direct input from OFF bipolar cell terminals that could drive glycine release onto postsynaptic RGCs (Demb \& Singer, 2012; Veruki, Mørkve, \& Hartveit, 2003; Xin \& Bloomfield, 1999). It is also possible that a common All input to certain OFF RGC types could synchronize their outputs and simultaneously desynchronize the outputs of ON RGCs (Murphy \& Rieke, 2006, 2008). More generally, the inhibition between the ON and OFF pathways, or so-called crossover inhibition, may increase encoding efficiency for contrast (Liang \& Freed, 2012). Revealing the specific role for direct All connection in visual information processing will require genetic manipulation of these connections in future studies.

\section{ACKNOWLEDGMENTS}

This work was supported by NIH grants EY014454, EY07003, EY026878 and unrestricted awards from Research to Prevent
Blindness to University of Michigan and Yale University. We thank Joshua Singer and Joseph Pottackal for comments on the manuscript.

\section{CONFLICT OF INTEREST}

The authors have no conflicting interests.

\section{ORCID}

Jonathan B. Demb (iD http://orcid.org/0000-0003-2227-9041

\section{REFERENCES}

Anderson, J. R., Jones, B. W., Watt, C. B., Shaw, M. V., Yang, J. H., Demill, D., ... Marc, R. E. (2011). Exploring the retinal connectome. Molecular Vision, 17, 355-379.

Arman, A. C., \& Sampath, A. P. (2012). Dark-adapted response threshold of OFF ganglion cells is not set by OFF bipolar cells in the mouse retina. Journal of Neurophysiology, 107, 2649-2659.

Baden, T., Berens, P., Franke, K., Roman Roson, M., Bethge, M., \& Euler, T. (2016). The functional diversity of retinal ganglion cells in the mouse. Nature, 529, 345-350.

Balakrishnan, V., Puthussery, T., Kim, M. H., Taylor, W. R., \& von Gersdorff, H. (2015). Synaptic vesicle exocytosis at the dendritic lobules of an inhibitory interneuron in the mammalian retina. Neuron, 87, 563-575

Beaudoin, D. L., Borghuis, B. G., \& Demb, J. B. (2007). Cellular basis for contrast gain control over the receptive field center of mammalian retinal ganglion cells. Journal of Neuroscience, 27, 2636-2645.

Beaudoin, D. L., Manookin, M. B., \& Demb, J. B. (2008). Distinct expressions of contrast gain control in parallel synaptic pathways converging on a retinal ganglion cell. Journal of Physiology, 586, 5487-5502.

Behrens, C., Schubert, T., Haverkamp, S., Euler, T., \& Berens, P. (2016). Connectivity map of bipolar cells and photoreceptors in the mouse retina. elife, 5, e20041.

Bloomfield, S. A., \& Dacheux, R. F. (2001). Rod vision: Pathways and processing in the mammalian retina. Progress in Retina and Eye Research, 20, 351-384.

Bloomfield, S. A., Xin, D., \& Osborne, T. (1997). Light-induced modulation of coupling between All amacrine cells in the rabbit retina. Visual Neuroscience, 14, 565-576.

Borghuis, B. G., Looger, L. L., Tomita, S., \& Demb, J. B. (2014). Kainate receptors mediate signaling in both transient and sustained OFF bipolar cell pathways in mouse retina. Journal of Neuroscience, 34, 6128-6139.

Borghuis, B. G., Marvin, J. S., Looger, L. L., \& Demb, J. B. (2013). Twophoton imaging of nonlinear glutamate release dynamics at bipolar cell synapses in the mouse retina. Journal of Neuroscience, 33, 10972-10985.

Brainard, D. H. (1997). The Psychophysics Toolbox. Spatial Vision, 10, 433-436.

Buldyrev, I., Puthussery, T., \& Taylor, W. R. (2012). Synaptic pathways that shape the excitatory drive in an OFF retinal ganglion cell. Journal of Neurophysiology, 107, 1795-1807.

Chen, S., \& Diamond, J. S. (2002). Synaptically released glutamate activates extrasynaptic NMDA receptors on cells in the ganglion cell layer of rat retina. Journal of Neuroscience, 22, 2165-2173.

Cohen, E., \& Sterling, P. (1990). Demonstration of cell types among cone bipolar neurons of cat retina. Philosophical Transactions of the Royal Society of London Series B, Biolological Sciences, 330, 305-321. 
Cohen, E. D. (1998). Interactions of inhibition and excitation in the lightevoked currents of $X$ type retinal ganglion cells. Journal of Neurophysiology, 80, 2975-2990.

Deans, M. R., Volgyi, B., Goodenough, D. A., Bloomfield, S. A., \& Paul, D. L. (2002). Connexin36 is essential for transmission of rod-mediated visual signals in the mammalian retina. Neuron, 36, 703-712.

Demb, J. B., \& Singer, J. H. (2012). Intrinsic properties and functional circuitry of the All amacrine cell. Visual Neuroscience, 29, 51-60.

Demb, J. B., \& Singer, J. H. (2015). Functional circuitry of the retina. Annual Review of Vision Science, 1, 263-289.

Demb, J. B., Zaghloul, K., Haarsma, L., \& Sterling, P. (2001). Bipolar cells contribute to nonlinear spatial summation in the brisk-transient $(\mathrm{Y})$ ganglion cell in mammalian retina. Journal of Neuroscience, 21, 7447-7454.

DeVries, S. H. (2000). Bipolar cells use kainate and AMPA receptors to filter visual information into separate channels. Neuron, 28, 847-856.

Euler, T., Haverkamp, S., Schubert, T., \& Baden, T. (2014). Retinal bipolar cells: Elementary building blocks of vision. Nature Reviews Neuroscience, 15, 507-519.

Farrow, K., Teixeira, M., Szikra, T., Viney, T. J., Balint, K., Yonehara, K., \& Roska, B. (2013). Ambient illumination toggles a neuronal circuit switch in the retina and visual perception at cone threshold. Neuron, 78, 325-338.

Field, G. D., Greschner, M., Gauthier, J. L., Rangel, C., Shlens, J., Sher, A., ... Chichilnisky, E. J. (2009). High-sensitivity rod photoreceptor input to the blue-yellow color opponent pathway in macaque retina. Nature Neuroscience, 12, 1159-1164.

Franke, K., Berens, P., Schubert, T., Bethge, M., Euler, T., \& Baden, T. (2017). Inhibition decorrelates visual feature representations in the inner retina. Nature, 542, 439-444.

Freed, M. A., \& Liang, Z. (2010). Reliability and frequency response of excitatory signals transmitted to different types of retinal ganglion cell. Journal of Neurophysiology, 103, 1508-1517.

Habermann, C. J., O'Brien, B. J., Wässle, H., \& Protti, D. A. (2003). All amacrine cells express L-type calcium channels at their output synapses. Journal of Neuroscience, 23, 6904-6913.

Hack, I., Peichl, L., \& Brandstätter, J. H. (1999). An alternative pathway for rod signals in the rodent retina: Rod photoreceptors, cone bipolar cells, and the localization of glutamate receptors. Proceedings of the National Academy of Sciences of the United States of America, 96, 14130-14135.

Hannibal, J., Christiansen, A. T., Heegaard, S., Fahrenkrug, J., \& Kiilgaard, J. F. (2017). Melanopsin expressing human retinal ganglion cells: Subtypes, distribution, and intraretinal connectivity. The Journal of Comparative Neurology, 525, 1934-1961.

Homann, J., \& Freed, M. A. (2017). A mammalian retinal ganglion cell implements a neuronal computation that maximizes the SNR of its postsynaptic currents. Journal of Neuroscience, 37, 1468-1478.

Ichinose, T., \& Hellmer, C. B. (2016). Differential signalling and glutamate receptor compositions in the OFF bipolar cell types in the mouse retina. Journal of Physiology, 594, 883-894.

Jacoby, J., Zhu, Y., DeVries, S. H., \& Schwartz, G. W. (2015). An amacrine cell circuit for signaling steady illumination in the retina. Cell Reports, $13,2663-2670$.

Ke, J. B., Wang, Y. V., Borghuis, B. G., Cembrowski, M. S., Riecke, H., Kath, W. L., ... Singer, J. H. (2014). Adaptation to background light enables contrast coding at rod bipolar cell synapses. Neuron, 81, 388-401.

Koch, K., McLean, J., Segev, R., Freed, M. A., Berry, M. J., 2nd, Balasubramanian, V., \& Sterling, P. (2006). How much the eye tells the brain. Current Biology, 16, 1428-1434.

Kolb, H., \& Nelson, R. (1993). OFF-alpha and OFF-beta ganglion cells in cat retina: II. Neural circuitry as revealed by electron microscopy of HRP stains. The Journal of Comparative Neurology, 329, 85-110.
Krishnaswamy, A., Yamagata, M., Duan, X., Hong, Y. K., \& Sanes, J. R. (2015). Sidekick 2 directs formation of a retinal circuit that detects differential motion. Nature, 524, 466-470.

Lee, E. J., Kim, H. J., Kim, I. B., Park, J. H., Oh, S. J., Rickman, D. W., \& Chun, M. H. (2003). Morphological analysis of disabled-1immunoreactive amacrine cells in the guinea pig retina. The Journal of Comparative Neurology, 466, 240-250.

Li, S., Woodfin, M., Long, S. S., \& Fuerst, P. G. (2016). IPLaminator: An ImageJ plugin for automated binning and quantification of retinal lamination. BMC Bioinformatics, 17, 36.

Li, W., Keung, J. W., \& Massey, S. C. (2004). Direct synaptic connections between rods and OFF cone bipolar cells in the rabbit retina. The Journal of Comparative Neurology, 474, 1-12.

Liang, Z., \& Freed, M. A. (2010). The ON pathway rectifies the OFF pathway of the mammalian retina. Journal of Neuroscience, 30, 5533-5543.

Liang, Z., \& Freed, M. A. (2012). Cross inhibition from ON to OFF pathway improves the efficiency of contrast encoding in the mammalian retina. Journal of Neurophysiology, 108, 2679-2688.

Lin, B., Jakobs, T. C., \& Masland, R. H. (2005). Different functional types of bipolar cells use different gap-junctional proteins. Journal of Neuroscience, 25, 6696-6701.

Lindstrom, S. H., Ryan, D. G., Shi, J., \& DeVries, S. H. (2014). Kainate receptor subunit diversity underlying response diversity in retinal off bipolar cells. Journal of Physiology, 592, 1457-1477.

Manookin, M. B., Beaudoin, D. L., Ernst, Z. R., Flagel, L. J., \& Demb, J. B. (2008). Disinhibition combines with excitation to extend the operating range of the OFF visual pathway in daylight. Journal of Neuroscience, 28, 4136-4150.

Manookin, M. B., Weick, M., Stafford, B. K., \& Demb, J. B. (2010). NMDA receptor contributions to visual contrast coding. Neuron, 67, 280-293.

Marc, R. E., Anderson, J. R., Jones, B. W., Sigulinsky, C. L., \& Lauritzen, J. S. (2014). The All amacrine cell connectome: A dense network hub. Frontiers in Neural Circuits, 8, 104.

Margolis, D. J., \& Detwiler, P. B. (2007). Different mechanisms generate maintained activity in ON and OFF retinal ganglion cells. Journal of Neuroscience, 27, 5994-6005.

Maxeiner, S., Dedek, K., Janssen-Bienhold, U., Ammermuller, J., Brune, H., Kirsch, T., ... Weiler, R. (2005). Deletion of connexin45 in mouse retinal neurons disrupts the rod/cone signaling pathway between All amacrine and $\mathrm{ON}$ cone bipolar cells and leads to impaired visual transmission. Journal of Neuroscience, 25, 566-576.

Mazade, R. E., \& Eggers, E. D. (2013). Light adaptation alters the source of inhibition to the mouse retinal OFF pathway. Journal of Neurophysiology, 110, 2113-2128.

Miller, R. F. (2008). Cell communication mechanisms in the vertebrate retina the proctor lecture. Investigative Ophthalmology and Visual Science, 49, 5184-5198.

Mills, S. L., \& Massey, S. C. (1995). Differential properties of two gap junctional pathways made by All amacrine cells. Nature, 377, 734-737.

Mills, S. L., O'Brien, J. J., Li, W., O'Brien, J., \& Massey, S. C. (2001). Rod pathways in the mammalian retina use connexin 36. Journal of Comparative Neurology, 436, 336-350.

Müller, F., Wässle, H., \& Voigt, T. (1988). Pharmacological modulation of the rod pathway in the cat retina. Journal of Neurophysiology, 59, 1657-1672.

Münch, T. A., da Silveira, R. A., Siegert, S., Viney, T. J., Awatramani, G. B., \& Roska, B. (2009). Approach sensitivity in the retina processed by a multifunctional neural circuit. Nature Neuroscience, 12, 13081316. 
Murphy, G. J., \& Rieke, F. (2006). Network variability limits stimulus-evoked spike timing precision in retinal ganglion cells. Neuron, 52, 511-524.

Murphy, G. J., \& Rieke, F. (2008). Signals and noise in an inhibitory interneuron diverge to control activity in nearby retinal ganglion cells. Nature Neuroscience, 11, 318-326.

Nelson, R. (1982). All amacrine cells quicken time course of rod signals in the cat retina. Journal of Neurophysiology, 47, 928-947.

Pang, J. J., Abd-El-Barr, M. M., Gao, F., Bramblett, D. E., Paul, D. L., \& Wu, S. M. (2007). Relative contributions of rod and cone bipolar cell inputs to All amacrine cell light responses in the mouse retina. Journal of Physiology, 580, 397-410.

Pang, J. J., Gao, F., Paul, D. L., \& Wu, S. M. (2012). Rod, M-cone and M/ $\mathrm{S}$-cone inputs to hyperpolarizing bipolar cells in the mouse retina. Journal of Physiology, 590, 845-854.

Park, S. J., Borghuis, B. G., Rahmani, P., Zeng, Q., Kim, I. J., \& Demb, J. B. (2015). Function and circuitry of VIP+ interneurons in the mouse retina. Journal of Neuroscience, 35, 10685-10700.

Peters, A., \& Feldman, M. L. (1976). The projection of the lateral geniculate nucleus to area 17 of the rat cerebral cortex. I. General description. Journal of Neurocytology, 5, 63-84.

Protti, D. A., Flores-Herr, N., Li, W., Massey, S. C., \& Wässle, H. (2005). Light signaling in scotopic conditions in the rabbit, mouse and rat retina: A physiological and anatomical study. Journal of Neurophysiology, 93, 3479-3488.

Sanes, J. R., \& Masland, R. H. (2015). The types of retinal ganglion cells: Current status and implications for neuronal classification. Annual Review of Neuroscience, 38, 221-246.

Shekhar, K., Lapan, S. W., Whitney, I. E., Tran, N. M., Macosko, E. Z., Kowalczyk, M., ... Sanes, J. R. (2016). Comprehensive classification of retinal bipolar neurons by single-cell transcriptomics. Cell, 166, 1308-1323.e30.

Singer, J. H., \& Diamond, J. S. (2003). Sustained Ca2+ entry elicits transient postsynaptic currents at a retinal ribbon synapse. Journal of Neuroscience, 23, 10923-10933.

Soucy, E., Wang, Y., Nirenberg, S., Nathans, J., \& Meister, M. (1998). A novel signaling pathway from rod photoreceptors to ganglion cells in mammalian retina. Neuron, 21, 481-493.
Stepanyants, A., \& Chklovskii, D. B. (2005). Neurogeometry and potential synaptic connectivity. Trends in Neurosciences, 28, 387-394.

Strettoi, E., Raviola, E., \& Dacheux, R. F. (1992). Synaptic connections of the narrow-field, bistratified rod amacrine cell (All) in the rabbit retina. The Journal of Comparative Neurology, 325, 152-168.

Trexler, E. B., Li, W., \& Massey, S. C. (2005). Simultaneous contribution of two rod pathways to All amacrine and cone bipolar cell light responses. Journal of Neurophysiology, 93, 1476-1485.

van Wyk, M., Wässle, H., \& Taylor, W. R. (2009). Receptive field properties of ON- and OFF-ganglion cells in the mouse retina. Visual Neuroscience, 26, 297-308.

Vaney, D. I., Sivyer, B., \& Taylor, W. R. (2012). Direction selectivity in the retina: Symmetry and asymmetry in structure and function. Nature Reviews Neuroscience, 13, 194-208.

Veruki, M. L., \& Hartveit, E. (2002). Electrical synapses mediate signal transmission in the rod pathway of the mammalian retina. Journal of Neuroscience, 22, 10558-10566.

Veruki, M. L., Mørkve, S. H., \& Hartveit, E. (2003). Functional properties of spontaneous EPSCs and non-NMDA receptors in rod amacrine (All) cells in the rat retina. Journal of Physiology, 549, 759-774.

Wässle, H., Puller, C., Müller, F., \& Haverkamp, S. (2009). Cone contacts, mosaics, and territories of bipolar cells in the mouse retina. Journal of Neuroscience, 29, 106-117.

Xin, D., \& Bloomfield, S. A. (1999). Comparison of the responses of All amacrine cells in the dark- and light-adapted rabbit retina. Visual Neuroscience, 16, 653-665.

Yin, L., Smith, R. G., Sterling, P., \& Brainard, D. H. (2006). Chromatic properties of horizontal and ganglion cell responses follow a dual gradient in cone opsin expression. Journal of Neuroscience, 26, 12351-12361.

How to cite this article: Beaudoin DL, Kupershtok M, Demb JB. Selective synaptic connections in the retinal pathway for night vision. J Comp Neurol. 2019;527:117-132. https://doi.org/10. 1002/cne.24313 